\title{
Long-term Effects of Training Systems and Rootstocks on 'McIntosh' and 'Honeycrisp' Performance, a 20-year Study in a Northern Cold Climate- Part 2: Economic Analysis
}

\author{
Jaume Lordan ${ }^{1}$ \\ Department of Horticulture, NYSAES, Cornell University, Geneva, NY 14456
}

Anna Wallis

Cornell Cooperative Extension, Eastern NY Commercial Horticulture Program, Cornell University, Plattsburgh, NY 12901

Poliana Francescatto and Terence L. Robinson Department of Horticulture, NYSAES, Cornell University, Geneva, NY 14456

Additional index words. break-even year to positive NPV (BYPNPV), high-density, Malus $\times$ domestica, net present value (NPV), PCA, profitability, sensitivity analysis

\begin{abstract}
Orchard profitability relies on multiple factors such as cultivar, planting density, training system, rootstock, and fruit quality but is also strongly affected by growing climate and soil resources. To evaluate orchard profitability in a northern cold climate, a field trial was planted in Peru, Clinton County, NY, in 2002, with two apple cultivars (Honeycrisp and McIntosh), where we compared the Central Leader (CL) training system on 'M.M.111' rootstock; Slender Pyramid (SP) on 'M.26' and 'Geneva ${ }^{\circledR}$ 30' ('G.30'); Vertical Axis (VA) on 'M.9 (Nic $\left.{ }^{\circledR} 29\right)$ ' ('M.9'), 'Budagovsky 9' ('B.9'), and 'G.16'; SolAxe (SA) on 'M.9', 'B.9', and 'G.16'; and Tall Spindle (TS) on 'M.9', 'B.9', and 'G.16'. CL was planted at 539 trees/ha, SP at 1097 trees/ha, VA and SA at 1794 trees/ha, and TS at 3230 trees/ha. The aim of this study was to evaluate the economic profitability of 'Honeycrisp' and 'McIntosh' at a wide range of planting densities, training systems, and rootstocks for cold areas such as northern New York state. A secondary goal was to assess the effect of various economic factors on the net present value (NPV) of each combination of training system, rootstock, and density. High NPV was achieved with 'Honeycrisp' $(\approx \mathbf{\$ 4 5 0 , 0 0 0 / h a})$, whereas NPV was significantly lower with 'McIntosh' $(\approx \$ 80,000 / \mathrm{ha})$. Within $\approx 5$ years, 'Honeycrisp' planted in a TS $(3230$ trees/ha) reached a positive NPV, whereas 9 years were needed when 'Honeycrisp' was planted in a CL system at 539 trees/ha. With 'McIntosh', break-even year to positive NPV (BYPNPV) was reached at 9 years for TS on 'M.9'. Most of the other training system and rootstock combinations needed up to 11-13 years to show a positive NPV. The most important variables affecting orchard NPV in our trial were fruit price and yield. The best option for 'Honeycrisp' in northern New York State appears to be TS on either 'B.9' or 'M.9', whereas with 'McIntosh', the best option appears to be TS on 'M.9'.
\end{abstract}

Orchard profitability is the main goal when planting a new orchard. However, profitability relies on multiple factors such as cultivar, planting density, training system, rootstock, and fruit quality (Bravin et al., 2009; DeMaree, 1995; DeMarree et al., 2003; Elkins et al., 2008; Goedegebure, 1993;

Received for publication 2 Apr. 2018. Accepted for publication 7 May 2018.

This research was partially supported by the New York Apple Research Development Program.

We wish to thank Everett Orchards for all the resources invested in this trial. We thank Peter Herzeelle and Kevin Iungerman for field and laboratory support.

${ }^{1}$ Corresponding author. E-mail: j13325@cornell. edu.
Heijerman et al., 2015; Lordan et al., 2017a; Robinson et al., 2007; Sansavini and Musacchi, 2002; Walsh et al., 2011; White and DeMarree, 1992). How a cultivar adapts to each location will determine how the interaction of the aforementioned factors will succeed in providing a profitable outcome. Therefore, cultivar selection is key for each particular location. New York State is the second largest apple producer in the United States, after Washington State, averaging around 0.6 million tons of production annually (www.nyapplecountry.com). Within New York State, the northern region named the Champlain Valley could be considered as the 'McIntosh' apple capital of the world. With an average yearly temperature of $7.5^{\circ} \mathrm{C}$ and a mean annual rainfall of $800 \mathrm{~mm}$, the humid and cold climate of the Champlain
Valley requires specific cultivars adapted to such harsh conditions. 'McIntosh', because of its cold-hardiness, is one of the main cultivars grown in the northeastern United States and eastern Canada (Ferree and Warrington, 2003). In recent years, 'Honeycrisp' was suggested as one of the few cultivars which could challenge 'McIntosh' as the most widely grown cultivar in New England (Greene and Weis, 2001). 'Honeycrisp' also has a much higher fruit price in the market than 'McIntosh', which has a large impact on orchard profitability.

Advances in new training systems and rootstock breeding programs have changed the way apples are grown in modern orchards (Fazio, 2014; Fazio et al., 2015; Robinson, 2008a; Robinson et al., 2011c). Dwarfing apple rootstocks, especially 'M.9' and 'M.26', have made possible the transition of entire industries to higher tree densities $(>1000$ trees/ha) and training systems over the last 50 years. The Cornell University apple rootstock breeding project has developed rootstock genotypes which are better adapted than 'M.9' and 'M.26' to the biotic stresses common in eastern North America (Cummins and Aldwinckle, 1983; Fazio et al., 2015). Among them, 'G.30' has been especially useful in northern climates with short growing seasons, whereas 'G.16' (Robinson et al., 2003), which has a similar growth and vigor to 'M.9' clones, has had only limited evaluation in northern climates. In addition, low-vigor cultivars such as Honeycrisp require a reevaluation of promising rootstocks when the scion cultivar is not vigorous (Robinson et al., 2011b).

Although several studies have reported a positive relationship between yield and planting density (Elkins and DeJong, 2002; Kappel and Brownlee, 2001; Robinson, 2008b; Sansavini and Musacchi, 2002; Vercammen, 1999), it is worth noting that there is a point where increasing planting density can decrease orchard profitability (Robinson, 2008a; Robinson et al., 2007). Therefore, the right selection of cultivar, planting density, training system, and rootstock for each particular location and economic environment needs to be evaluated over the long run.

The aim of this long-term study was to evaluate the economic profitability of 'Honeycrisp' and 'McIntosh' at a wide range of planting densities, training systems, and rootstocks for cold areas such as northern New York state. A secondary goal was to assess the effect of various economic factors on the profitability of each combination of training system, rootstock, and density.

\section{Materials and Methods}

Trial site and design. In 2002, we planted a 1.6-ha on-farm field trial in Peru, Clinton County, NY (lat. $44.597223^{\circ}$, long. $-73.545078^{\circ}$ ), with two apple (Malus $\times$ domextica Borkh.) cultivars (Honeycrisp and McIntosh). We compared the following (12) production systems: CL on 'M.M.111' rootstock; SP on 'M.26' and 'Geneva ${ }^{\circledR}$ 30' ('G.30'); VA on 'M.9 (Nic $\left.{ }^{\circledR} 29\right)$ ' ('M.9'), 
'Budagovsky 9' ('B.9'), and 'G.16'; SA on 'M.9', 'B.9', and 'G.16'; and TS on 'M.9', 'B.9', and 'G.16' (Table 1). CL was planted at 539 trees/ha, SP at 1097 trees/ha, VA and SA at 1794 trees/ha, and TS at 3230 trees/ha.

Experimental design was a randomized complete block with a split-split plot and three replications. Training system was the main plot with each main plot consisting of two (CL), four (SP), or six (VA, SA, and TS) 40-m long rows. Cultivar was the subplot, which consisted of one (CL), two (SP), or three (VA, SA, and TS) 40-m long rows. Rootstock was the sub-subplot with each subsubplot consisting of a single $40-\mathrm{m}$ row. There were 72 rows of $40 \mathrm{~m}$ each with 24 rows in each replication containing randomized main plots (system), randomized subplots (cultivar) within the main plots, and randomized sub-subplots (rootstock) within the subplots. The treatment structure was an incomplete factorial of four systems, two cultivars, and six rootstocks with only 24 out of 48 possible combinations of cultivar $\times$ training system $\times$ rootstock. The number of trees in each sub-subplot depended on planting density and varied from 13 trees/row for CL, 18 for SP, 25 for SA and VA, and 38 for TS.

Soil type was a Bombay loam with good water-holding capacity, moderately well drained, and fertile. The site had previously been planted to apple trees on seedling rootstock for 40 years and was not fumigated. The replant disease severity at the trial site was not evaluated before planting, but field fumigation trials in the same county by Merwin et al. (2001) showed low replant disease pressure for similar soils. The site was prepared by removing the old orchard, tilling the soil to remove old root, liming the soil with $5 \mathrm{t}$ of high mag lime, and then cropping with Sudan grass [Sorghum $\times$ drummondii (Steud.) Millsp. \& Chas] for 2 years before planting the experiment. The plot was laid out perpendicular to the old orchard rows, thus giving a balanced effect of the location of the old trees on each rootstock and system. The trees were trickle-irrigated as needed during the growing season using the Cornell apple irrigation model based on a modified Penman-Monteith equation (NEWA.org) (Robinson et al., 2017) and received from 200 to $1000 \mathrm{~mm}$ of water depending on the year. Average annual precipitation for Peru, NY, is $812 \mathrm{~mm}$. The trial was managed with conventional pesticides and fertilizers according to industry standards (Agnello et al., 2003).

Tree management. All of the trees had three to five feathers at planting. CL system was supported by a steel conduit pipe $(3 \mathrm{~m}$ with $0.6 \mathrm{~m}$ in the ground) at each tree. SP, $\mathrm{VA}$, and SA trees were supported by a singlewire trellis $(2.3 \mathrm{~m})$ connected to a steel conduit pipe ( $3 \mathrm{~m}$ with $15 \mathrm{~cm}$ in the ground) at each tree (Robinson and Hoying, 1999). TS systems were supported by a 3 -wire trellis $(2.5 \mathrm{~m})$.

CL trees were developed by initially heading each tree at $70 \mathrm{~cm}$ and thereafter annually heading the leader and lower tier scaffolds by one-third each year to produce a strong sturdy trunk and branch framework with permanent branches. Two permanent tiers of scaffold branches were developed,

Table 1. Spacing, tree planting density, training system, and rootstock evaluated at Peru, Clinton County, NY, 2002-16.

\begin{tabular}{lcll}
\hline Spacing $(\mathrm{m})$ & Planting density (trees/ha) & Training system & \multicolumn{1}{c}{ Rootstock } \\
\hline $3.05 \times 6.08$ & 539 & Central Leader & M.M.111 \\
$2.13 \times 4.28$ & 1,097 & Slender Pyramid & G.30 \\
& & & M.26 \\
$1.52 \times 3.67$ & 1,794 & SolAxe & B.9 \\
& & & G.16 \\
& & Vertical Axis & M.9 $\left(\mathrm{Nic}^{\circledR} 29\right)$ \\
& & & B.9 \\
& \multirow{2}{*}{3,230} & Tall Spindle & M.9 $\left(\mathrm{Nic}^{\circledR} 29\right)$ \\
$1.01 \times 3.06$ & & B.9 \\
& & & G.16 \\
& & & M.9 (Nic $\left.{ }^{\circledR} 29\right)$ \\
\hline
\end{tabular}

spaced $1 \mathrm{~m}$ apart, with four to five branches per tier. Limb spreading was performed in years 3 and 5 using wooden limb spreaders. Scaffold branches between the first and second tiers were removed between the years 5 and 6 . Tree height was limited to $5 \mathrm{~m}$.

SP and VA trees were developed by heading the leader at $120 \mathrm{~cm}$ above the graft union at planting and shortening each feather by one-third their length. In years 2 through 6 , leaders were not headed. In year 3 , fourfive lower scaffold branches were tied down to horizontal. Beginning in year 4, largediameter limbs $(>5 \mathrm{~cm})$ were removed back to the trunk with an angled cut to develop replacement limbs. Each year, two to three large branches were removed. Tree height was limited to $4 \mathrm{~m}$. With the VA, lateral branches were kept simple by removing sublateral branches to create a single axis for each branch. With the SP, sublateral branches were allowed to remain but were removed if they became as large as the main axis of the lateral branch.

SA trees were developed by heading the leader at $120 \mathrm{~cm}$ above the graft union at planting, removing one to three of the largest feathers, and leaving the remaining feathers unpruned. In years 2 through 4 , the leaders were not headed. Beginning in year 4 and continuing in years 6 and 8 , scaffold branches longer than $1 \mathrm{~m}$ and originating above $120 \mathrm{~cm}$ height on the trunk were tied down below horizontal $\left(\approx 120^{\circ}\right.$ from vertical), and one to two scaffold branches originating below $120 \mathrm{~cm}$ on the trunk were removed each year until no branches were left below $120 \mathrm{~cm}$. Tree height was limited to $4 \mathrm{~m}$ by bending the top of the tree horizontal at $4 \mathrm{~m}$ height in year 8 . Sublateral branches on the lateral branches were allowed to develop producing a highly branched scaffold with "fingers."

TS trees were developed by heading the leader at $150 \mathrm{~cm}$ above the graft union at planting, removing one to two of the largest feathers and leaving the remaining feathers unpruned. In years 2 through 4 , the leaders were left unheaded. Beginning in year 3, large-diameter limbs $(>2 \mathrm{~cm})$ were removed back to the trunk with an angled cut to develop replacement limbs. Each year, one to two branches larger than $2 \mathrm{~cm}$ were removed. Tree height was limited to $3.5 \mathrm{~m}$. Only small lateral branches $(<2 \mathrm{~cm})$ were

Table 2. Grower returns $(\$ / \mathrm{kg})$ for each cultivar, color category, and fruit size category after subtracting storage and packing charges. These included packing charge, MCP (1-methylcyclopropene) treatment, and average cost between regular and CA storage. Values were taken from statewide averages of New York State apple industry.

\begin{tabular}{|c|c|c|c|c|c|c|c|c|c|c|}
\hline \multicolumn{2}{|c|}{ Grower returns $(\$ / \mathrm{kg})$} & \multicolumn{9}{|c|}{ Fruit size } \\
\hline Color category & Cultivar & $\overline{<115 \mathrm{~g}}$ & $115<133 \mathrm{~g}$ & $133<153 \mathrm{~g}$ & $153<175 \mathrm{~g}$ & $175<199 \mathrm{~g}$ & $199<225 \mathrm{~g}$ & $225<253 \mathrm{~g}$ & $253<283 \mathrm{~g}$ & $\geq 283 \mathrm{~g}$ \\
\hline$\overline{X X}$ fancy & McIntosh & -0.01 & 0.19 & 0.94 & 0.94 & 1.00 & 1.06 & 1.18 & 0.89 & 1.23 \\
\hline $\mathrm{X}$ fancy & McIntosh & -0.01 & 0.19 & 0.83 & 0.83 & 0.89 & 0.94 & 1.06 & 1.12 & 1.12 \\
\hline \multirow[t]{2}{*}{ Fancy } & Honeycrisp & -0.01 & 0.18 & 1.72 & 1.72 & 2.33 & 2.39 & 2.61 & 2.72 & 2.72 \\
\hline & McIntosh & -0.01 & 0.19 & 0.65 & 0.65 & 0.71 & 0.77 & 0.89 & 0.94 & 0.94 \\
\hline No. 1 & Honeycrisp & -0.01 & 0.18 & 1.56 & 1.56 & 2.17 & 2.22 & 2.44 & 2.55 & 2.55 \\
\hline Utility & McIntosh & -0.01 & 0.19 & 0.19 & 0.19 & 0.19 & 0.19 & 0.19 & 0.19 & 0.19 \\
\hline
\end{tabular}


allowed to remain in the tree and they were each kept simple by removing sublateral branches to create a single axis for each branch.

Yield, income, labor, and fixed costs. For each tree, we recorded yield $(\mathrm{kg})$ and fruit number annually. From 2007 onward, we collected an 18-kg fruit sample from each subplot and assessed flesh firmness (Fruit Texture Analyzer; QA Supplies LLC, Norfolk, VA) and sugar content (Atago USA, Inc.,

Table 3. Costs used in the economic analysis. Values were estimated from statewide averages of New York State apple growers.

\begin{tabular}{ll}
\hline Pre plant costs & \\
\hline Land value & $\$ 6,000 / \mathrm{ha}$ \\
Land preparation & $\$ 1,800 / \mathrm{ha}$ \\
Labor: planting and training & $\$ 900 / \mathrm{ha}$ \\
Trellising & $\$ 10 / \mathrm{post}$ \\
$\quad$ Post cost & $\$ 1.6 / \mathrm{stake}$ \\
$\quad$ Conduit/stake cost & $\$ 0.03 / \mathrm{m}$ \\
$\quad$ Wire cost & $\$ 200 / \mathrm{ha}$ \\
Post pounding & $\$ 520 / \mathrm{ha}$ \\
Labor: trellis install & \\
Miscellaneous & $\$ 2,500 / \mathrm{ha}$ \\
Irrigation material & $\$ 1,000 / \mathrm{ha}$ \\
$\quad$ Irrigation install labor & \\
Financials & $5 \%$ \\
Interest rate (discount rate) & $\$ 1,500 / \mathrm{ha}$ \\
Annual fixed cost & $\$ 15 / \mathrm{h}$ \\
Skilled labor & $\$ 12 / \mathrm{h}$ \\
\hline Unskilled labor &
\end{tabular}

Table 4. Costs used in the economic analysis. Values were estimated from statewide averages of New York State apple growers.

\begin{tabular}{lll}
\hline & Honeycrisp & McIntosh \\
\hline Base picking cost & $\$ 35 /$ bin & $\$ 24 / \mathrm{bin}$ \\
Picking employer taxes & $15 \%$ & $15 \%$ \\
Total picking cost per bin & $\$ 40 / \mathrm{bin}$ & $\$ 28 / \mathrm{bin}$ \\
Total picking cost per $\mathrm{kg}$ & $\$ 0.11 / \mathrm{kg}$ & $\$ 0.08 / \mathrm{kg}$ \\
Feathered tree & $\$ 10.0 /$ tree & $\$ 9.0 /$ tree \\
\hline z $\$ 0.5 /$ tree are discounted when buying more than \\
1,000 trees $/$ ha.
\end{tabular}

Bellevue, WA) (Torres et al., 2017). The sample was graded for color and size by an electronic color and weight sizer machine (MAF Industries, Inc., Traver, CA). Fruit color was assessed as a percentage of skin surface colored red (according to USDA color standards). From these data, we calculated a simulated packout for our trials. Packout returns were taken from statewide averages of typical New York State apple industry (Table 2) and were used for both economic and sensitivity analysis. We also recorded annual labor time for tree training and pruning (2006-09, 2011, and 2014). The fruit growers labor crew was used to perform all pruning and training tasks where we recorded labor time to give realistic labor costs. Yield, fruit packout (fruit size and color), and labor input data were based on the trial. Average values were used for those years when fruit quality and pruning time were not assessed. Pruning and training costs were calculated as skilled labor at $\$ 15 / \mathrm{h}$ (Table 3).

Fixed costs were calculated at $\$ 1500 /$ ha (Table 3) and included the cost of management by the owner/manager and an overhead charge for farm-wide costs (real estate taxes, insurance, utilities, equipment replacement/ investment cost, and charge for miscellaneous farm-wide expenses). The fixed costs were based on the average fruit farm in New York State of 100 ha in a manner similar to White and DeMarree (1992). Total fixed costs per farm were divided by 100 to calculate the fixed costs per ha. Other costs were taken from statewide averages of New York State apple growers (Tables 3-5).

Economic calculations. We performed economic calculations of long-term orchard system profitability using NPV of accumulated and discounted annual cash flows for each cultivar, system, and planting density over 20 years (Casler et al., 1993; White and DeMarree, 1992). We used average data from 2014 to 2016 to estimate values for years 16 20. The analysis model we used to compare the 12 different combinations of training

Table 5. Annual costs (\$/ha) for disease, weed, and insect management; nutrition; and thinning. Values were estimated from statewide averages of New York State apple growers.

\begin{tabular}{rcccccc}
\hline & \multicolumn{3}{c}{ IPM (\$/ha) } & & & \multicolumn{2}{c}{ Thinning (\$/ha) } \\
\cline { 2 - 4 } Yr & Disease & Weed & Insects & Nutrition $(\$ /$ ha $)$ & Honeycrisp & McIntosh \\
\hline 0 & 0 & 54 & 0 & 642 & 0 & 0 \\
1 & 290 & 91 & 122 & 978 & 0 & 0 \\
2 & 398 & 97 & 121 & 236 & 45 & 30 \\
3 & 679 & 28 & 396 & 497 & 121 & 45 \\
4 & 733 & 99 & 642 & 406 & 181 & 60 \\
5 & 824 & 145 & 760 & 702 & 181 & 80 \\
6 & 691 & 48 & 929 & 475 & 181 & 80 \\
7 & 668 & 99 & 719 & 565 & 181 & 80 \\
8 & 838 & 142 & 533 & 611 & 181 & 80 \\
9 & 838 & 142 & 727 & 565 & 181 & 80 \\
10 & 838 & 142 & 727 & 475 & 181 & 80 \\
11 & 838 & 142 & 727 & 563 & 181 & 80 \\
12 & 838 & 142 & 727 & 563 & 181 & 80 \\
13 & 838 & 142 & 727 & 563 & 181 & 80 \\
14 & 838 & 142 & 727 & 563 & 181 & 80 \\
15 & 838 & 142 & 727 & 563 & 181 & 80 \\
16 & 838 & 142 & 727 & 563 & 181 & 80 \\
17 & 838 & 142 & 727 & 563 & 181 & 80 \\
18 & 838 & 142 & 727 & 563 & & 80 \\
19 & 838 & 142 & 727 & 563 & 563 & 80 \\
20 & 838 & 142 & 727 & & & 0 \\
\hline
\end{tabular}

system and rootstock using NPV. This analysis considered the time value of money using discounted annual cash flows (a dollar received today is worth more than a dollar received in 10 years). NPV is the sum of discounted annual cash flows over 20 years using a fixed discount rate (DR). The DR was determined by subtracting the rate of inflation from the current interest rate to arrive at a real rate of interest. We used a 5\% rate DR for our basic comparisons. NPV was obtained for each treatment and year by applying the following formula:

$$
\mathrm{NPV}=\sum_{t=1}^{T} \frac{C_{t}}{(1+r)^{t}}-C_{0}
$$

where $C_{\mathrm{t}}=$ net cash inflow during period $t$; $C_{0}=$ total investment costs; $r=$ discount rate; and $t=$ number of time periods.

With NPV analysis, if the NPV of accumulated profit reaches zero, the investment is sound at the selected DR (White and DeMarree, 1992). The year that the NPV of accumulated profit reaches zero is the year in which the investment has been recouped with interest, and in the case of an orchard, is the year in which the orchard can be removed and replanted.

Sensitivity analysis. We performed a sensitivity analysis to study the effect of tree price, fruit price, yield, DR, labor, and land cost on orchard profitability for the optimum planting density and tree shape of each cultivar. In the calculation of NPV, we used different values for these factors to simulate different scenarios that can affect orchard profitability. Therefore, following the same methodology used for the economic analysis (Tables 2-17), we re-calculated the NPV value for each combination of cultivar, training system, and rootstock over a 20-year period, changing the values of the aforementioned factors. The criteria to set these different values were based on our experience and New York industry standards to provide a wide range of scenarios. Trial data and average statewide apple industry costs (Tables 2-5) were used. Reference tree price used for the economic analysis (Table 4) was increased by $15 \%, 25 \%$, and $50 \%$. Reference fruit price (Table 2) was reduced and increased by $15 \%$ and $25 \%$. Average yield obtained from the trial $(100 \%)$ was modified to $60 \%, 80 \%, 120 \%$, and $140 \%$. Land cost was assessed at $\$ 6000 / \mathrm{ha}$, which is typical of land value in northern New York state where the study was carried out and at $\$ 15,000 / \mathrm{ha}$, which is typical of Washington State, which is the largest apple-growing area in the United States. Different DRs (5\%, 7\%, and $9 \%$ ) were also assessed. Reference labor cost (Tables 3 and 4 ) was increased by $5 \%, 15 \%$, $25 \%$, and $50 \%$ to simulate expected increases in labor cost into the future.

Statistical analysis. We analyzed the effect of treatment variables (cultivar, system, and rootstock) on response variables (NPVs) by analysis of variance using linear mixed effect models. Mixed models including cultivar and the 12 combinations of training system $\times$ rootstock as a fixed factor, and 
Table 6. Gross income ( $\$$ ha) for each combination of training system (Central Leader - CL, SolAxe - SA, Slender Pyramid—SP, Tall Spindle—TS, and Vertical Axis-VA) and rootstock ('M.M.111', 'B.9', 'G.16', 'M.9', 'G.30', and 'M.26') for 'Honeycrisp' at Peru, Clinton County, NY, over 15 years. These data represent packout returns using Table 2 and the trial data (yield, fruit size, and fruit quality).

\begin{tabular}{|c|c|c|c|c|c|c|c|c|c|c|c|c|c|c|}
\hline \multicolumn{3}{|c|}{ Honeycrisp } & \multicolumn{12}{|c|}{ Gross income $(\$ / \mathrm{ha})$} \\
\hline & & $\mathrm{Yr}$ & $\overline{\text { CL M.M.111 }}$ & SP G.30 & SP M.26 & SA B.9 & SA G.16 & SA M.9 & VA B.9 & VA G.16 & VA M.9 & TS B.9 & TS G.16 & TS M.9 \\
\hline & 2002 & 1 & $\$-$ & $\$-$ & $\$-$ & $\$-$ & $\$-$ & $\$-$ & $\$-$ & $\$-$ & $\$-$ & $\$-$ & $\$-$ & $\$-$ \\
\hline & 2004 & 3 & $\$ 111$ & $\$ 1,961$ & $\$ 3,360$ & $\$ 7,224$ & $\$ 2,439$ & $\$ 8,894$ & $\$ 7,832$ & $\$ 4,271$ & $\$ 11,352$ & $\$ 23,568$ & $\$ 3,495$ & $\$ 13,877$ \\
\hline & 2005 & 4 & $\$ 2,655$ & $\$ 7,816$ & $\$ 10,741$ & $\$ 19,201$ & $\$ 16,341$ & $\$ 30,530$ & $\$ 17,180$ & $\$ 17,250$ & $\$ 25,066$ & $\$ 39,276$ & $\$ 38,835$ & $\$ 43,877$ \\
\hline & 2006 & 5 & $\$ 1,659$ & $\$ 24,197$ & $\$ 11,222$ & $\$ 34,392$ & $\$ 31,093$ & $\$ 20,859$ & $\$ 34,167$ & $\$ 18,788$ & $\$ 26,344$ & $\$ 46,472$ & $\$ 13,281$ & $\$ 15,740$ \\
\hline & 2007 & 6 & $\$ 10,170$ & $\$ 50,659$ & $\$ 37,803$ & $\$ 43,553$ & $\$ 51,849$ & $\$ 53,878$ & $\$ 51,005$ & $\$ 63,818$ & $\$ 64,017$ & $\$ 61,979$ & $\$ 77,276$ & $\$ 77,294$ \\
\hline & 2010 & 9 & 71 & $\$ 76,908$ & $\$ 28,370$ & $\$ 47,124$ & $\$ 42,998$ & $\$ 48,239$ & 116 & 280 & $\$ 54$ & $\$ 60,516$ & $\$ 77,301$ & $\$ 67,160$ \\
\hline & 2011 & 10 & $\$ 21,504$ & $\$ 33,818$ & $\$ 19,119$ & $\$ 35,711$ & $\$ 9,189$ & $\$ 37,779$ & $\$ 20,632$ & $\$ 4,885$ & $\$ 45,984$ & $\$ 54,215$ & $\$ 40,476$ & $\$ 80,712$ \\
\hline & 2012 & 11 & $\$ 67,059$ & $\$ 114,929$ & $\$ 55,368$ & $\$ 82,559$ & $\$ 68,813$ & $\$ 61,060$ & $\$ 81,514$ & $\$ 55,517$ & $\$ 63,178$ & $\$ 73,307$ & $\$ 72,601$ & $\$ 75,522$ \\
\hline & 2013 & 12 & $\$ 38,736$ & $\$ 78,337$ & $\$ 54,850$ & $\$ 70,032$ & $\$ 54,884$ & $\$ 49,660$ & $\$ 84,961$ & $\$ 59,905$ & $\$ 70,015$ & $\$ 60,516$ & $\$ 55,631$ & $\$ 48,961$ \\
\hline & 2014 & 13 & $\$ 66,163$ & $\$ 101,765$ & $\$ 49,248$ & $\$ 42,282$ & $\$ 54,282$ & $\$ 45,579$ & $\$ 66,857$ & $\$ 54,626$ & $\$ 72,380$ & $\$ 53,060$ & $\$ 69,572$ & $\$ 57,378$ \\
\hline & 2015 & 14 & $\$ 29,859$ & $\$ 61,243$ & $\$ 28,627$ & $\$ 51,687$ & $\$ 41,129$ & $\$ 44,160$ & $\$ 71,802$ & $\$ 48,826$ & $\$ 51,646$ & $\$ 47,959$ & $\$ 47,375$ & $\$ 44,393$ \\
\hline & 2016 & 15 & $\$ 95,675$ & $\$ 86,962$ & $\$ 53,289$ & $\$ 43,135$ & $\$ 63,985$ & $\$ 52,556$ & $\$ 44,790$ & $\$ 52,049$ & $\$ 84,819$ & $\$ 69,269$ & $\$ 51,437$ & $\$ 55,446$ \\
\hline
\end{tabular}

Table 7. Fixed, variable, and establishment costs (\$/ha) for each combination of training system (Central Leader —CL, SolAxe—SA, Slender Pyramid—SP, Tall Spindle-TS, and Vertical Axis-VA) and rootstock ('M.M.111', 'B.9', 'G.16', 'M.9', 'G.30', and 'M.26') for 'Honeycrisp' at Peru, Clinton County, NY, over 15 years. These data are calculated using Tables $3-5$ and the trial data (planting density).

\begin{tabular}{|c|c|c|c|c|c|c|c|c|c|c|c|c|c|c|c|}
\hline \multicolumn{2}{|c|}{ Honeycrisp } & $\begin{array}{c}\text { Fixed } \\
\text { cost } \\
(\$ / h a)\end{array}$ & $\begin{array}{c}\text { Variable } \\
\text { cost } \\
(\$ / \mathrm{ha})\end{array}$ & \multicolumn{12}{|c|}{$\begin{array}{c}\text { Establishment } \\
\text { cost }(\$ / \mathrm{ha})\end{array}$} \\
\hline Trial data & 0 & $\$-$ & $\$ 696$ & $\$ 7,800$ & $\$ 7,800$ & $\$ 7,800$ & $\$ 7,800$ & $\$ 7,800$ & $\$ 7,800$ & $\$ 7,800$ & $\$ 7,800$ & $\$ 7,800$ & $\$ 7,800$ & $\$ 7,800$ & $\$ 7,800$ \\
\hline
\end{tabular}

Table 8. Pruning cost ( $\$$ ha) for each combination of training system (Central Leader - CL, SolAxe—SA, Slender Pyramid—SP, Tall Spindle—TS, and Vertical Axis-VA) and rootstock ('M.M.111', 'B.9', 'G.16', 'M.9', 'G.30', and 'M.26') for 'Honeycrisp' at Peru, Clinton County, NY, over 15 years. These data are calculated using Table 3 (skilled labor $\$ 15 / \mathrm{ha}$ ) and the trial data (pruning/training time).

\begin{tabular}{|c|c|c|c|c|c|c|c|c|c|c|c|c|c|}
\hline \multicolumn{2}{|c|}{ Honeycrisp } & \multicolumn{12}{|c|}{ Pruning cost $(\$ /$ ha $)$} \\
\hline & $\mathrm{Yr}$ & CL M.M.111 & SP G.30 & SP M.26 & SA B.9 & SA G.16 & SA M.9 & VA B.9 & VA G.16 & VA M.9 & TS B.9 & TS G.16 & TS M.9 \\
\hline \multirow{12}{*}{ Trial data } & 1 & $\$ 200$ & $\$ 409$ & $\$ 293$ & $\$ 335$ & $\$ 598$ & $\$ 562$ & $\$ 275$ & $\$ 526$ & $\$ 466$ & $\$ 906$ & $\$ 1,069$ & $\$ 641$ \\
\hline & 3 & $\$ 120$ & $\$ 245$ & $\$ 176$ & $\$ 201$ & $\$ 359$ & $\$ 337$ & $\$ 165$ & $\$ 316$ & $\$ 280$ & $\$ 544$ & $\$ 641$ & $\$ 385$ \\
\hline & 4 & $\$ 1,104$ & $\$ 327$ & $\$ 234$ & $\$ 2,968$ & $\$ 3,178$ & $\$ 3,149$ & $\$ 220$ & $\$ 421$ & $\$ 373$ & $\$ 725$ & $\$ 855$ & $\$ 513$ \\
\hline & 5 & $\$ 200$ & $\$ 409$ & $\$ 293$ & $\$ 335$ & $\$ 598$ & $\$ 562$ & $\$ 275$ & $\$ 526$ & $\$ 466$ & $\$ 906$ & $\$ 1,069$ & $\$ 641$ \\
\hline & 6 & $\$ 283$ & $\$ 531$ & $\$ 479$ & $\$ 2,578$ & $\$ 2,662$ & $\$ 2,709$ & $\$ 693$ & $\$ 741$ & $\$ 657$ & $\$ 1,190$ & $\$ 1,037$ & $\$ 1,327$ \\
\hline & 9 & $\$ 445$ & $\$ 702$ & $\$ 456$ & $\$ 669$ & $\$ 766$ & $\$ 744$ & $\$ 578$ & $\$ 641$ & $\$ 650$ & $\$ 729$ & $\$ 689$ & $\$ 772$ \\
\hline & 10 & $\$ 532$ & $\$ 767$ & $\$ 488$ & $\$ 1,350$ & $\$ 1,548$ & $\$ 1,398$ & $\$ 514$ & $\$ 669$ & $\$ 609$ & $\$ 793$ & $\$ 850$ & $\$ 615$ \\
\hline & 11 & $\$ 445$ & $\$ 702$ & $\$ 456$ & $\$ 669$ & $\$ 766$ & $\$ 744$ & $\$ 578$ & $\$ 641$ & $\$ 650$ & $\$ 729$ & $\$ 689$ & $\$ 772$ \\
\hline & 12 & $\$ 460$ & $\$ 702$ & $\$ 456$ & $\$ 669$ & $\$ 766$ & $\$ 744$ & $\$ 578$ & $\$ 641$ & $\$ 650$ & $\$ 729$ & $\$ 689$ & $\$ 772$ \\
\hline & 13 & $\$ 774$ & $\$ 1,075$ & $\$ 683$ & $\$ 580$ & $\$ 753$ & $\$ 645$ & $\$ 896$ & $\$ 825$ & $\$ 896$ & $\$ 28$ & $\$ 18$ & $\$ 18$ \\
\hline & 14 & $\$ 438$ & $\$ 702$ & $\$ 456$ & $\$ 670$ & $\$ 766$ & $\$ 743$ & $\$ 578$ & $\$ 641$ & $\$ 650$ & $\$ 728$ & $\$ 690$ & $\$ 773$ \\
\hline & 15 & $\$ 445$ & $\$ 702$ & $\$ 456$ & $\$ 670$ & $\$ 766$ & $\$ 743$ & $\$ 578$ & $\$ 641$ & $\$ 650$ & $\$ 728$ & $\$ 690$ & $\$ 773$ \\
\hline
\end{tabular}

Table 9. Harvest cost (\$ha) for each combination of training system (Central Leader —CL, SolAxe-SA, Slender Pyramid—SP, Tall Spindle—TS, and Vertical Axis-VA) and rootstock ('M.M.111', 'B.9', 'G.16', 'M.9', 'G.30', and 'M.26') for 'Honeycrisp' at Peru, Clinton County, NY, over 15 years. These data are calculated using Table 4 (harvest cost) and the trial data (yield).

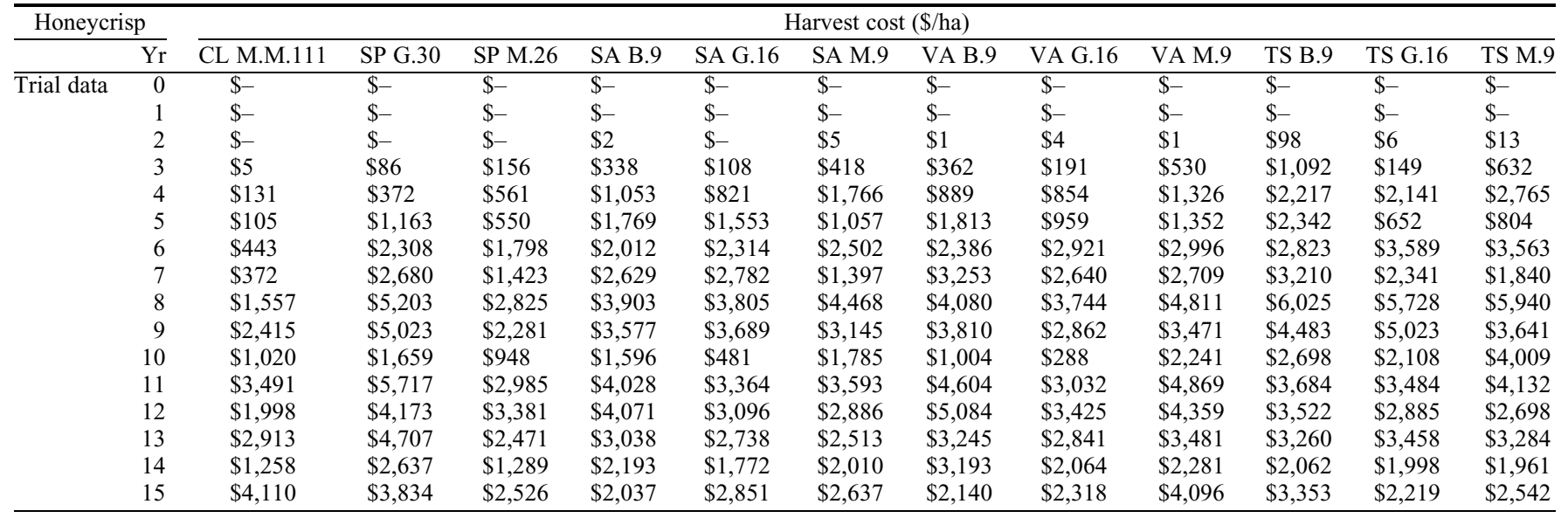


Table 10. Net cash (\$/ha) for each combination of training system (Central Leader — CL, SolAxe - SA, Slender Pyramid—SP, Tall Spindle—TS, and Vertical Axis-VA) and rootstock ('M.M.111', 'B.9', 'G.16', 'M.9', 'G.30', and 'M.26') for 'Honeycrisp' at Peru, Clinton County, NY, over 15 years. These data are calculated using Tables 6-9. Average trial data from 2014 to 2016 (years 13-15) were used to estimate values for years 16-20.

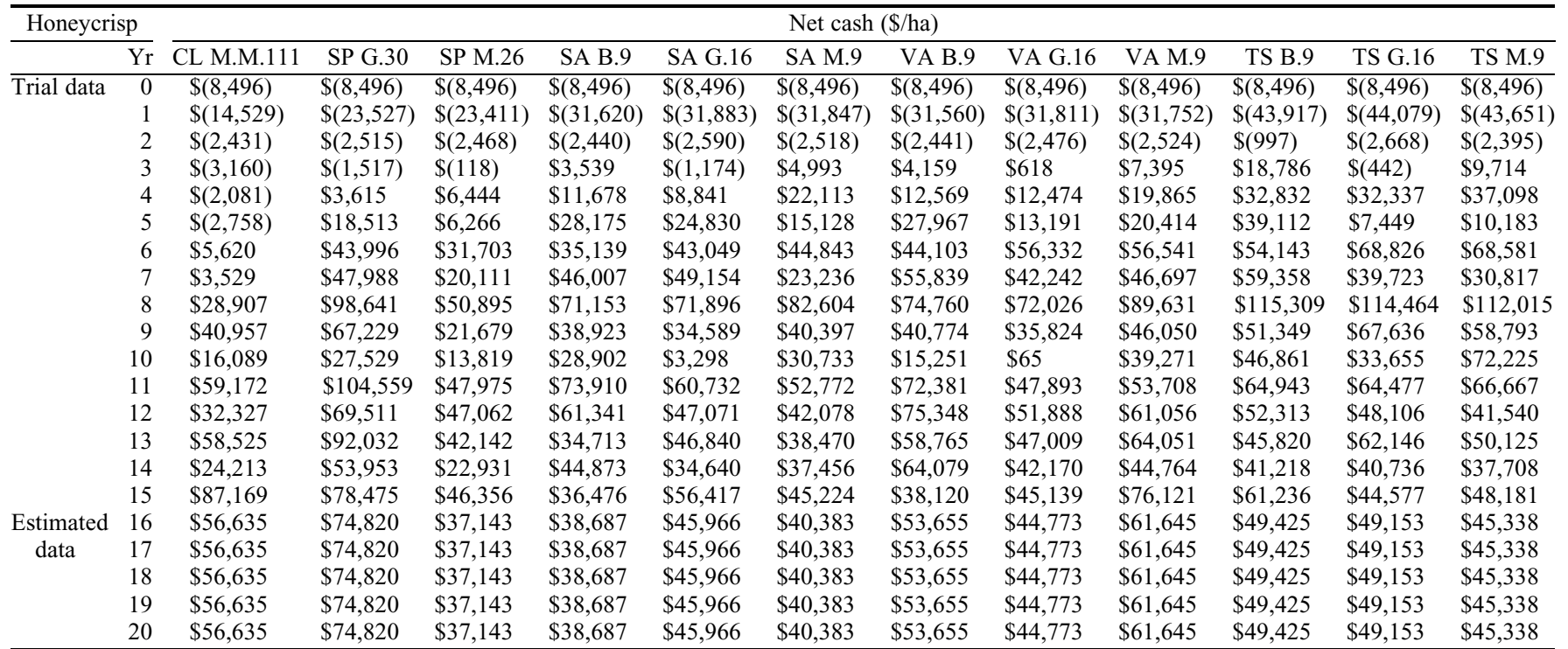

Table 11. Annual net present value (NPV, \$ha) for each combination of training system (Central Leader—CL, SolAxe-SA, Slender Pyramid—SP, Tall Spindle-TS, and Vertical Axis-VA) and rootstock ('M.M.111', 'B.9', 'G.16', 'M.9', 'G.30', and 'M.26') for 'Honeycrisp' at Peru, Clinton County, NY, over 15 years. These data are calculated using a discount rate of $5 \%$ (Table 3 ).

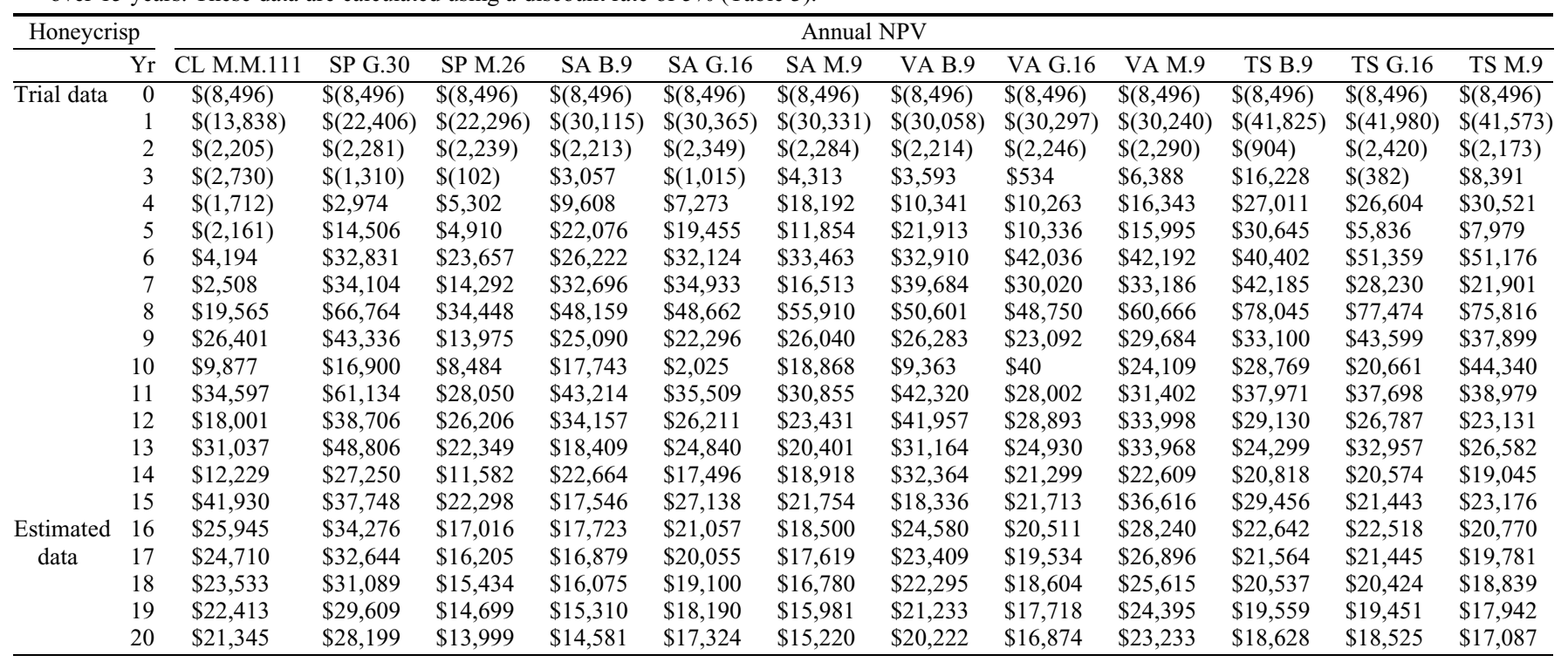

Table 12. Gross income (\$/ha) for each combination of training system (Central Leader - CL, SolAxe - SA, Slender Pyramid — SP, Tall Spindle —TS, and Vertical Axis-VA) and rootstock ('M.M.111', 'B.9', 'G.16', 'M.9', 'G.30', and 'M.26') for 'McIntosh' at Peru, Clinton County, NY, over 15 years. These data represent packout returns using Table 2 and the trial data (yield, fruit size, and fruit quality).

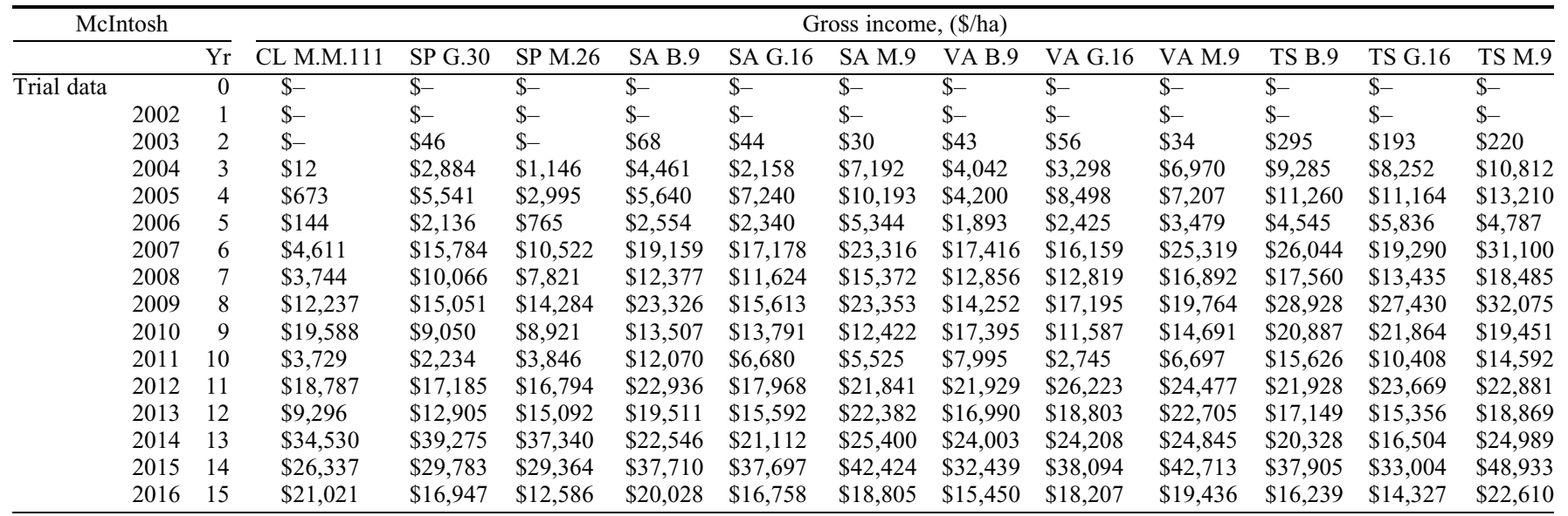


Table 13. Fixed, variable, and establishment costs ( $\$$ ha) for each combination of training system (Central Leader - CL, SolAxe-SA, Slender Pyramid—SP, Tall Spindle-TS, and Vertical Axis-VA) and rootstock ('M.M.111', 'B.9', 'G.16', 'M.9', 'G.30', and 'M.26') for 'McIntosh' at Peru, Clinton County, NY, over 15 years. These data are calculated using Tables $3-5$ and the trial data (planting density).

\begin{tabular}{|c|c|c|c|c|c|c|c|c|c|c|c|c|c|c|c|}
\hline \multicolumn{2}{|c|}{ McIntosh } & $\begin{array}{l}\text { Fixed } \\
\text { cost } \\
(\$ / h a)\end{array}$ & $\begin{array}{c}\text { Variable } \\
\text { cost } \\
(\$ / \mathrm{ha})\end{array}$ & \multicolumn{12}{|c|}{$\begin{array}{l}\text { Establishment } \\
\text { cost }(\$ / \mathrm{ha})\end{array}$} \\
\hline Trial data & 0 & $\$-$ & $\$ 696$ & $\$ 7,800$ & $\$ 7,800$ & $\$ 7,800$ & $\$ 7,800$ & $\$ 7,800$ & $\$ 7,800$ & $\$ 7,800$ & $\$ 7,800$ & $\$ 7,800$ & $\$ 7,800$ & $\$ 7,800$ & $\$ 7,800$ \\
\hline
\end{tabular}

Table 14. Pruning cost (\$/ha) for each combination of training system (Central Leader —CL, SolAxe — SA, Slender Pyramid—SP, Tall Spindle—TS, and Vertical Axis-VA) and rootstock ('M.M.111', 'B.9', 'G.16', 'M.9', 'G.30', and 'M.26') for 'McIntosh' at Peru, Clinton County, NY, over 15 years. These data are calculated using Table 3 (skilled labor $\$ 15 /$ ha) and the trial data (pruning/training time).

\begin{tabular}{|c|c|c|c|c|c|c|c|c|c|c|c|c|c|}
\hline \multicolumn{2}{|c|}{ McIntosh } & \multicolumn{12}{|c|}{ Pruning cost $(\$ / \mathrm{ha})$} \\
\hline & $\overline{\mathrm{Yr}}$ & $\overline{\text { CL M.M.111 }}$ & SP G.30 & SP M.26 & SA B.9 & SA G.16 & SA M.9 & VA B.9 & VA G.16 & VA M.9 & TS B.9 & TS G.16 & TS M.9 \\
\hline & 1 & $\$ 235$ & $\$ 355$ & $\$ 264$ & $\$ 598$ & $\$ 574$ & $\$ 609$ & $\$ 442$ & $\$ 693$ & $\$ 586$ & $\$ 722$ & $\$ 878$ & $\$ 921$ \\
\hline & 4 & $\$ 1,132$ & $\$ 284$ & $\$ 211$ & $\$ 3,178$ & $\$ 3,159$ & $\$ 3,188$ & $\$ 354$ & $\$ 555$ & $\$ 468$ & $\$ 578$ & $\$ 702$ & $\$ 736$ \\
\hline & 5 & $\$ 235$ & $\$ 355$ & $\$ 264$ & $\$ 598$ & $\$ 574$ & $\$ 609$ & $\$ 442$ & $\$ 693$ & $\$ 586$ & $\$ 722$ & $\$ 878$ & $\$ 921$ \\
\hline & 6 & $\$ 318$ & $\$ 477$ & $\$ 345$ & $\$ 2,685$ & $\$ 2,686$ & $\$ 2,626$ & $\$ 645$ & $\$ 681$ & $\$ 825$ & $\$ 1,303$ & $\$ 1,459$ & $\$ 1,360$ \\
\hline & 9 & $\$ 704$ & $\$ 654$ & $\$ 522$ & $\$ 844$ & $\$ 853$ & $\$ 796$ & $\$ 615$ & $\$ 807$ & $\$ 748$ & $\$ 872$ & $\$ 982$ & $\$ 934$ \\
\hline & 10 & $\$ 1,051$ & $\$ 833$ & $\$ 660$ & $\$ 1,637$ & $\$ 1,709$ & $\$ 1,566$ & $\$ 562$ & $\$ 837$ & $\$ 693$ & $\$ 963$ & $\$ 1,119$ & $\$ 906$ \\
\hline & 11 & $\$ 704$ & $\$ 654$ & $\$ 522$ & $\$ 844$ & $\$ 853$ & $\$ 796$ & $\$ 615$ & $\$ 807$ & $\$ 748$ & $\$ 872$ & $\$ 982$ & $\$ 934$ \\
\hline & 12 & $\$ 704$ & $\$ 654$ & $\$ 522$ & $\$ 844$ & $\$ 853$ & $\$ 796$ & $\$ 615$ & $\$ 807$ & $\$ 748$ & $\$ 872$ & $\$ 982$ & $\$ 934$ \\
\hline & 13 & $\$ 1,320$ & $\$ 1,097$ & $\$ 792$ & $\$ 1,013$ & $\$ 1,040$ & $\$ 896$ & $\$ 884$ & $\$ 1,237$ & $\$ 944$ & $\$ 39$ & $\$ 74$ & $\$ 28$ \\
\hline & 14 & $\$ 704$ & $\$ 654$ & $\$ 522$ & $\$ 844$ & $\$ 853$ & $\$ 796$ & $\$ 617$ & $\$ 807$ & $\$ 748$ & $\$ 875$ & $\$ 984$ & $\$ 935$ \\
\hline & 15 & $\$ 704$ & $\$ 654$ & $\$ 522$ & $\$ 844$ & $\$ 853$ & $\$ 796$ & $\$ 617$ & $\$ 807$ & $\$ 748$ & $\$ 875$ & $\$ 984$ & $\$ 935$ \\
\hline
\end{tabular}

Table 15. Harvest cost (\$ha) for each combination of training system (Central Leader - CL, SolAxe-SA, Slender Pyramid-SP, Tall Spindle-TS, and Vertical Axis-VA) and rootstock ('M.M.111', 'B.9', 'G.16', 'M.9', 'G.30', and 'M.26') for 'McIntosh' at Peru, Clinton County, NY, over 15 years. These data are calculated using Table 4 (harvest cost) and the trial data (yield).

\begin{tabular}{|c|c|c|c|c|c|c|c|c|c|c|c|c|c|}
\hline \multicolumn{2}{|c|}{ McIntosh } & \multicolumn{12}{|c|}{ Harvest cost $(\$ / \mathrm{ha})$} \\
\hline & $\mathrm{Yr}$ & $\overline{\text { CL M.M.111 }}$ & SP G.30 & SP M.26 & SA B.9 & SA G.16 & SA M.9 & VA B.9 & VA G.16 & VA M.9 & TS B.9 & TS G.16 & TS M.9 \\
\hline & 1 & $\$-$ & $\$-$ & $\$-$ & $\$-$ & $\$-$ & $\$-$ & $\$-$ & $\$-$ & $\$-$ & $\$-$ & $\$-$ & $\$-$ \\
\hline & 4 & $\$ 80$ & $\$ 773$ & $\$ 370$ & $\$ 964$ & $\$ 1,101$ & $\$ 1,555$ & $\$ 806$ & $\$ 1,091$ & $\$ 1,070$ & $\$ 1,836$ & $\$ 1,821$ & $\$ 2,526$ \\
\hline & 5 & $\$ 24$ & $\$ 348$ & $\$ 166$ & $\$ 373$ & $\$ 506$ & $\$ 715$ & $\$ 325$ & $\$ 513$ & $\$ 499$ & $\$ 635$ & $\$ 1,096$ & $\$ 729$ \\
\hline & 6 & $\$ 509$ & $\$ 1,878$ & $\$ 1,243$ & $\$ 2,302$ & $\$ 2,176$ & $\$ 2,789$ & $\$ 2,299$ & $\$ 1,944$ & $\$ 3,762$ & $\$ 3,717$ & $\$ 2,593$ & $\$ 4,900$ \\
\hline & 9 & $\$ 2,542$ & $\$ 1,818$ & $\$ 1,881$ & $\$ 2,786$ & $\$ 3,336$ & $\$ 3,143$ & $\$ 2,826$ & $\$ 2,274$ & $\$ 3,041$ & $\$ 3,962$ & $\$ 3,714$ & $\$ 4,094$ \\
\hline & 10 & $\$ 573$ & $\$ 447$ & $\$ 640$ & $\$ 1,788$ & $\$ 1,154$ & $\$ 977$ & $\$ 1,305$ & $\$ 439$ & $\$ 1,174$ & $\$ 2,747$ & $\$ 1,712$ & $\$ 2,449$ \\
\hline & 11 & $\$ 4,689$ & $\$ 6,589$ & $\$ 6,051$ & $\$ 7,905$ & $\$ 6,641$ & $\$ 8,389$ & $\$ 7,668$ & $\$ 7,993$ & $\$ 8,534$ & $\$ 9,256$ & $\$ 7,526$ & $\$ 9,780$ \\
\hline & 12 & $\$ 1,258$ & $\$ 1,950$ & $\$ 2,082$ & $\$ 2,888$ & $\$ 2,315$ & $\$ 3,288$ & $\$ 2,496$ & $\$ 2,537$ & $\$ 3,561$ & $\$ 2,725$ & $\$ 2,324$ & $\$ 3,010$ \\
\hline & 13 & $\$ 3,501$ & $\$ 4,652$ & $\$ 4,174$ & $\$ 3,435$ & $\$ 3,346$ & $\$ 4,246$ & $\$ 3,449$ & $\$ 3,326$ & $\$ 3,980$ & $\$ 4,177$ & $\$ 3,433$ & $\$ 4,572$ \\
\hline & 14 & $\$ 3,132$ & $\$ 3,673$ & $\$ 3,424$ & $\$ 4,743$ & $\$ 4,453$ & $\$ 4,796$ & $\$ 4,102$ & $\$ 4,359$ & $\$ 5,223$ & $\$ 4,947$ & $\$ 3,968$ & $\$ 6,078$ \\
\hline & 15 & $\$ 3,477$ & $\$ 3,237$ & $\$ 2,737$ & $\$ 3,895$ & $\$ 3,370$ & $\$ 3,618$ & $\$ 3,404$ & $\$ 3,382$ & $\$ 4,309$ & $\$ 3,074$ & $\$ 2,619$ & $\$ 4,241$ \\
\hline
\end{tabular}

block as a random factor were built to analyze the effect of cultivar and treatment effects (training system and rootstock) on NPV. There was a strong interaction of cultivar and treatment; thus, a second analysis was performed for each cultivar and results are presented separately for each cultivar. Crop load was included as a covariate to adjust for fruit size. Separate analyses were performed to compare the systems (SA, VA, and TS) that had the same common rootstocks ('B.9', 'G.16', and 'M.9') and to compare those three rootstocks across the three systems. Therefore, mixed models including system or rootstock as fixed factor, and block nested to system or rootstock as random factor were built to separate treatment effects on NPV of each cultivar. All mean separations were carried out using Tukey's honestly significant difference $(P=0.05)$. Residual analysis was performed to insure that model assumptions were met. Multivariate projection methods principal component analysis (PCA) were applied to simultaneously analyze how different variables interact among them and with NPV. For this purpose, we used the following variables: NPV, reference tree price used for the economic analysis (Table 4) increased by $15 \%, 25 \%$, and $50 \%$; reference fruit price (Table 2) reduced and increased by $15 \%$ and $25 \%$; average yield obtained from the trial modified to $60 \%$,
$80 \%, 120 \%$, and $140 \%$; land cost at $\$ 15,000 / \mathrm{ha}$; DR at $7 \%$ and $9 \%$; and reference labor cost (Tables 3 and 4 ) increased by $5 \%$, $15 \%, 25 \%$, and $50 \%$. For each cultivar, all the variables were analyzed in the same matrix. Data were analyzed using the JMP statistical software package (Version 12; SAS Institute, Inc., Cary, NC).

\section{Results}

Economic analysis. Over 20 years, there was a great difference of orchard NPV depending on the cultivar (Table 18; Fig. 1) when using actual trial data and New York industry standard prices (Tables 2-5). 
Table 16. Net cash (\$/ha) for each combination of training system (Central Leader — CL, SolAxe—SA, Slender Pyramid—SP, Tall Spindle—TS, and Vertical Axis-VA) and rootstock ('M.M.111', 'B.9', 'G.16', 'M.9', 'G.30', and 'M.26') for 'McIntosh' at Peru, Clinton County, NY, over 15 years. These data are calculated using Tables 12-15. Average trial data from 2014 to 2016 (years 13-15) were used to estimate values for years 16-20.

\begin{tabular}{|c|c|c|c|c|c|c|c|c|c|c|c|c|c|}
\hline \multicolumn{2}{|l|}{ McIntosh } & \multicolumn{12}{|c|}{ Net cash $(\$ /$ ha $)$} \\
\hline & $\overline{\mathrm{Yr}}$ & $\overline{\text { CL M.M.111 }}$ & SP G.30 & SP M.26 & SA B.9 & SA G.16 & SA M.9 & VA B.9 & VA G.16 & VA M.9 & TS B.9 & TS G.16 & TS M.9 \\
\hline \multirow[t]{16}{*}{ Trial data } & 0 & $\$(8,496)$ & $\$(8,496)$ & $\$(8,496)$ & $\$(8,496)$ & $\$(8,496)$ & $\$(8,496)$ & $\$(8,496)$ & $\$(8,496)$ & $\$(8,496)$ & $\$(8,496)$ & $\$(8,496)$ & $\$(8,496)$ \\
\hline & 1 & $\$(14,025)$ & $\$(22,377)$ & $\$(22,285)$ & $\$(30,091)$ & $\$(30,067)$ & $\$(30,102)$ & $\$(29,935)$ & $\$(30,186)$ & $\$(30,079)$ & $\$(40,503)$ & $\$(40,659)$ & $\$(40,702)$ \\
\hline & 2 & $\$(2,445)$ & $\$(2,456)$ & $\$(2,457)$ & $\$(2,534)$ & $\$(2,544)$ & $\$(2,569)$ & $\$(2,493)$ & $\$(2,580)$ & $\$(2,557)$ & $\$(2,411)$ & $\$(2,556)$ & $\$(2,544)$ \\
\hline & 3 & $\$(3,262)$ & $\$(777)$ & $\$(2,264)$ & $\$ 481$ & $\$(1,586)$ & $\$ 2,913$ & $\$ 215$ & $\$(650)$ & $\$ 2,710$ & $\$ 4,598$ & $\$ 3,679$ & $\$ 5,980$ \\
\hline & 4 & $\$(3,964)$ & $\$ 1,057$ & $\$(1,012)$ & $\$(1,929)$ & $\$(446)$ & $\$ 2,023$ & $\$(386)$ & $\$ 3,425$ & $\$ 2,242$ & $\$ 5,420$ & $\$ 5,214$ & $\$ 6,522$ \\
\hline & 5 & $\$(4,106)$ & $\$(2,559)$ & $\$(3,656)$ & $\$(2,408)$ & $\$(2,731)$ & $\$ 28$ & $\$(2,866)$ & $\$(2,772)$ & $\$(1,597)$ & $\$(804)$ & $\$(129)$ & $\$(854)$ \\
\hline & 6 & $\$ 61$ & $\$ 9,706$ & $\$ 5,210$ & $\$ 10,450$ & $\$ 8,593$ & $\$ 14,178$ & $\$ 10,748$ & $\$ 9,811$ & $\$ 17,010$ & $\$ 17,301$ & $\$ 11,515$ & $\$ 21,117$ \\
\hline & 7 & $\$(748)$ & $\$ 4,329$ & $\$ 2,528$ & $\$ 6,498$ & $\$ 5,515$ & $\$ 9,045$ & $\$ 6,645$ & $\$ 6,516$ & $\$ 9,562$ & $\$ 10,069$ & $\$ 6,607$ & $\$ 10,561$ \\
\hline & 8 & $\$ 5,595$ & $\$ 8,581$ & $\$ 8,166$ & $\$ 13,905$ & $\$ 7,575$ & $\$ 13,838$ & $\$ 7,336$ & $\$ 10,164$ & $\$ 12,076$ & $\$ 18,683$ & $\$ 18,793$ & $\$ 21,733$ \\
\hline & 9 & $\$ 12,488$ & $\$ 2,723$ & $\$ 2,665$ & $\$ 6,023$ & $\$ 5,749$ & $\$ 4,629$ & $\$ 10,100$ & $\$ 4,653$ & $\$ 7,048$ & $\$ 12,200$ & $\$ 13,315$ & $\$ 10,570$ \\
\hline & 10 & $\$(1,657)$ & $\$(2,808)$ & $\$(1,217)$ & $\$ 4,882$ & $\$ 54$ & $\$(781)$ & $\$ 2,367$ & $\$(2,293)$ & $\$ 1,068$ & $\$ 8,154$ & $\$ 3,816$ & $\$ 7,474$ \\
\hline & 11 & $\$ 9,543$ & $\$ 6,091$ & $\$ 6,371$ & $\$ 10,337$ & $\$ 6,624$ & $\$ 8,805$ & $\$ 9,794$ & $\$ 13,573$ & $\$ 11,345$ & $\$ 7,950$ & $\$ 11,310$ & $\$ 8,317$ \\
\hline & 12 & $\$ 3,485$ & $\$ 6,450$ & $\$ 8,638$ & $\$ 11,928$ & $\$ 8,573$ & $\$ 14,447$ & $\$ 10,028$ & $\$ 11,609$ & $\$ 14,545$ & $\$ 9,702$ & $\$ 8,199$ & $\$ 11,075$ \\
\hline & 13 & $\$ 25,858$ & $\$ 29,676$ & $\$ 28,523$ & $\$ 14,247$ & $\$ 12,876$ & $\$ 16,407$ & $\$ 15,819$ & $\$ 15,795$ & $\$ 16,070$ & $\$ 12,262$ & $\$ 9,146$ & $\$ 16,538$ \\
\hline & 14 & $\$ 18,651$ & $\$ 21,605$ & $\$ 21,567$ & $\$ 28,273$ & $\$ 28,540$ & $\$ 32,981$ & $\$ 23,870$ & $\$ 29,078$ & $\$ 32,892$ & $\$ 28,233$ & $\$ 24,202$ & $\$ 38,069$ \\
\hline & 15 & $\$ 12,990$ & $\$ 9,206$ & $\$ 5,477$ & $\$ 11,438$ & $\$ 8,684$ & $\$ 10,540$ & $\$ 7,579$ & $\$ 10,169$ & $\$ 10,529$ & $\$ 8,440$ & $\$ 6,873$ & $\$ 13,584$ \\
\hline \multirow[t]{5}{*}{ Estimated data } & 16 & $\$ 19,166$ & $\$ 20,163$ & $\$ 18,523$ & $\$ 17,986$ & $\$ 16,700$ & $\$ 19,976$ & $\$ 15,756$ & $\$ 18,347$ & $\$ 19,830$ & $\$ 16,311$ & $\$ 13,407$ & $\$ 22,730$ \\
\hline & 17 & $\$ 19,166$ & $\$ 20,163$ & $\$ 18,523$ & $\$ 17,986$ & $\$ 16,700$ & $\$ 19,976$ & $\$ 15,756$ & $\$ 18,347$ & $\$ 19,830$ & $\$ 16,311$ & $\$ 13,407$ & $\$ 22,730$ \\
\hline & 18 & $\$ 19,166$ & $\$ 20,163$ & $\$ 18,523$ & $\$ 17,986$ & $\$ 16,700$ & $\$ 19,976$ & $\$ 15,756$ & $\$ 18,347$ & $\$ 19,830$ & $\$ 16,311$ & $\$ 13,407$ & $\$ 22,730$ \\
\hline & 19 & $\$ 19,166$ & $\$ 20,163$ & $\$ 18,523$ & $\$ 17,986$ & $\$ 16,700$ & $\$ 19,976$ & $\$ 15,756$ & $\$ 18,347$ & $\$ 19,830$ & $\$ 16,311$ & $\$ 13,407$ & $\$ 22,730$ \\
\hline & 20 & $\$ 19,166$ & $\$ 20,163$ & $\$ 18,523$ & $\$ 17,986$ & $\$ 16,700$ & $\$ 19,976$ & $\$ 15,756$ & $\$ 18,347$ & $\$ 19,830$ & $\$ 16,311$ & $\$ 13,407$ & $\$ 22,730$ \\
\hline
\end{tabular}

Table 17. Annual net present value (NPV, \$/ha) for each combination of training system (Central Leader-CL, SolAxe-SA, Slender Pyramid—SP, Tall Spindle_TS, and Vertical Axis_-VA) and rootstock ('M.M.111', 'B.9', 'G.16', 'M.9', 'G.30', and 'M.26') for 'McIntosh' at Peru, Clinton County, NY, over 15 years. These data are calculated using a discount rate of 5\% (Table 3 ).

\begin{tabular}{|c|c|c|c|c|c|c|c|c|c|c|c|c|c|}
\hline \multicolumn{2}{|l|}{ McIntosh } & \multicolumn{12}{|c|}{ Annual NPV } \\
\hline & $\overline{\mathrm{Yr}}$ & CL M.M.111 & SP G.30 & SP M.26 & SA B.9 & SA G.16 & SA M.9 & VA B.9 & VA G.16 & VA M.9 & TS B.9 & TS G.16 & TS M.9 \\
\hline \multirow[t]{16}{*}{ Trial data } & 0 & $\$(8,496)$ & $\$(8,496)$ & $\$(8,496)$ & $\$(8,496)$ & $\$(8,496)$ & $\$(8,496)$ & $\$(8,496)$ & $\$(8,496)$ & $\$(8,496)$ & $\$(8,496)$ & $\$(8,496)$ & $\$(8,496)$ \\
\hline & 1 & $\$(13,357)$ & $\$(21,311)$ & $\$(21,224)$ & $\$(28,658)$ & $\$(28,635)$ & $\$(28,669)$ & $\$(28,510)$ & $\$(28,749)$ & $\$(28,646)$ & $\$(38,575)$ & $\$(38,723)$ & $\$(38,763)$ \\
\hline & 2 & $\$(2,218)$ & $\$(2,227)$ & $\$(2,228)$ & $\$(2,298)$ & $\$(2,307)$ & $\$(2,331)$ & $\$(2,261)$ & $\$(2,340)$ & $\$(2,319)$ & $\$(2,187)$ & $\$(2,319)$ & $\$(2,307)$ \\
\hline & 3 & $\$(2,818)$ & $\$(671)$ & $\$(1,956)$ & $\$ 415$ & $\$(1,370)$ & $\$ 2,517$ & $\$ 186$ & $\$(561)$ & $\$ 2,341$ & $\$ 3,972$ & $\$ 3,178$ & $\$ 5,165$ \\
\hline & 4 & $\$(3,261)$ & $\$ 870$ & $\$(833)$ & $\$(1,587)$ & $\$(367)$ & $\$ 1,665$ & $\$(318)$ & $\$ 2,818$ & $\$ 1,845$ & $\$ 4,459$ & $\$ 4,290$ & $\$ 5,365$ \\
\hline & 5 & $\$(3,217)$ & $\$(2,005)$ & $\$(2,865)$ & $\$(1,886)$ & $\$(2,140)$ & $\$ 22$ & $\$(2,245)$ & $\$(2,172)$ & $\$(1,252)$ & $\$(630)$ & $\$(101)$ & $\$(669)$ \\
\hline & 6 & $\$ 46$ & $\$ 7,243$ & $\$ 3,888$ & $\$ 7,798$ & $\$ 6,413$ & $\$ 10,580$ & $\$ 8,021$ & $\$ 7,321$ & $\$ 12,693$ & $\$ 12,910$ & $\$ 8,593$ & $\$ 15,758$ \\
\hline & 7 & $\$(532)$ & $\$ 3,076$ & $\$ 1,797$ & $\$ 4,618$ & $\$ 3,919$ & $\$ 6,428$ & $\$ 4,722$ & $\$ 4,631$ & $\$ 6,796$ & $\$ 7,156$ & $\$ 4,695$ & $\$ 7,506$ \\
\hline & 8 & $\$ 3,787$ & $\$ 5,808$ & $\$ 5,527$ & $\$ 9,411$ & $\$ 5,127$ & $\$ 9,366$ & $\$ 4,966$ & $\$ 6,879$ & $\$ 8,173$ & $\$ 12,645$ & $\$ 12,720$ & $\$ 14,710$ \\
\hline & 9 & $\$ 8,050$ & $\$ 1,756$ & $\$ 1,718$ & $\$ 3,883$ & $\$ 3,706$ & $\$ 2,984$ & $\$ 6,511$ & $\$ 3,000$ & $\$ 4,543$ & $\$ 7,864$ & $\$ 8,583$ & $\$ 6,813$ \\
\hline & 10 & $\$(1,017)$ & $\$(1,724)$ & $\$(747)$ & $\$ 2,997$ & $\$ 33$ & $\$(479)$ & $\$ 1,453$ & $\$(1,408)$ & $\$ 655$ & $\$ 5,006$ & $\$ 2,342$ & $\$ 4,588$ \\
\hline & 11 & $\$ 5,580$ & $\$ 3,561$ & $\$ 3,725$ & $\$ 6,044$ & $\$ 3,873$ & $\$ 5,148$ & $\$ 5,727$ & $\$ 7,936$ & $\$ 6,633$ & $\$ 4,648$ & $\$ 6,612$ & $\$ 4,863$ \\
\hline & 12 & $\$ 1,940$ & $\$ 3,591$ & $\$ 4,810$ & $\$ 6,642$ & $\$ 4,774$ & $\$ 8,045$ & $\$ 5,584$ & $\$ 6,464$ & $\$ 8,099$ & $\$ 5,402$ & $\$ 4,566$ & $\$ 6,167$ \\
\hline & 13 & $\$ 13,713$ & $\$ 15,738$ & $\$ 15,127$ & $\$ 7,556$ & $\$ 6,828$ & $\$ 8,701$ & $\$ 8,389$ & $\$ 8,376$ & $\$ 8,522$ & $\$ 6,503$ & $\$ 4,850$ & $\$ 8,770$ \\
\hline & 14 & $\$ 9,420$ & $\$ 10,912$ & $\$ 10,893$ & $\$ 14,280$ & $\$ 14,415$ & $\$ 16,658$ & $\$ 12,056$ & $\$ 14,686$ & $\$ 16,613$ & $\$ 14,260$ & $\$ 12,224$ & $\$ 19,228$ \\
\hline & 15 & $\$ 6,248$ & $\$ 4,428$ & $\$ 2,635$ & $\$ 5,502$ & $\$ 4,177$ & $\$ 5,070$ & $\$ 3,646$ & $\$ 4,891$ & $\$ 5,064$ & $\$ 4,060$ & $\$ 3,306$ & $\$ 6,534$ \\
\hline \multirow[t]{5}{*}{ Estimated data } & 16 & $\$ 8,780$ & $\$ 9,237$ & $\$ 8,485$ & $\$ 8,240$ & $\$ 7,650$ & $\$ 9,151$ & $\$ 7,218$ & $\$ 8,405$ & $\$ 9,085$ & $\$ 7,472$ & $\$ 6,142$ & $\$ 10,413$ \\
\hline & 17 & $\$ 8,362$ & $\$ 8,797$ & $\$ 8,081$ & $\$ 7,847$ & $\$ 7,286$ & $\$ 8,715$ & $\$ 6,874$ & $\$ 8,005$ & $\$ 8,652$ & $\$ 7,117$ & $\$ 5,850$ & $\$ 9,917$ \\
\hline & 18 & $\$ 7,964$ & $\$ 8,378$ & $\$ 7,697$ & $\$ 7,474$ & $\$ 6,939$ & $\$ 8,300$ & $\$ 6,547$ & $\$ 7,624$ & $\$ 8,240$ & $\$ 6,778$ & $\$ 5,571$ & $\$ 9,445$ \\
\hline & 19 & $\$ 7,585$ & $\$ 7,979$ & $\$ 7,330$ & $\$ 7,118$ & $\$ 6,609$ & $\$ 7,905$ & $\$ 6,235$ & $\$ 7,261$ & $\$ 7,848$ & $\$ 6,455$ & $\$ 5,306$ & $\$ 8,995$ \\
\hline & 20 & $\$ 7,224$ & $\$ 7,599$ & $\$ 6,981$ & $\$ 6,779$ & $\$ 6,294$ & $\$ 7,529$ & $\$ 5,938$ & $\$ 6,915$ & $\$ 7,474$ & $\$ 6,148$ & $\$ 5,053$ & $\$ 8,567$ \\
\hline
\end{tabular}

Although high NPV was achieved with 'Honeycrisp' ( $\approx \$ 450,000 / \mathrm{ha})$, for 'McIntosh', the highest values were $\$ 100,000 /$ ha with TS on 'M.9', whereas the rest of the treatments were between $\$ 40,000$ and $\$ 80,000 /$ ha after 20 years.

With 'Honeycrisp', the highest cumulative NPVs were attained with TS with 'M.9', 'B.9', and 'G.16'; VA with 'M.9' and 'B.9'; and SP with 'G.30'. The lowest NPV was for CL with 'M.M.111' and SP with 'M.26' (Fig. 1; Table 18). There were no significant differences among TS, VA, and SA or among rootstocks ('B.9', 'G.16', and 'M.9') when comparing within systems that had the same common rootstocks or within rootstock that had the same common systems, respectively.

With 'McIntosh', the highest NPV after 20 years was for TS with 'M.9', followed by VA and SA both with 'M.9', and TS with
'B.9'. On the other hand, SA with 'G.16' and SP with 'M.26' had the lowest NPV (Fig. 1; Table 18). There were no significant differences among TS, VA, and SA. On the other hand, 'M.9' had significantly higher NPV than 'G.16'.

Higher establishment costs were associated with the highest planting densities; therefore, the TS had the highest establishment costs $(\approx \$ 45,000 /$ ha) (Fig. 1; Tables 7 and 13). VA and SA had similar establishment costs $(\$ 35,000 / \mathrm{ha})$, followed by SP $(\$ 27,000 / \mathrm{ha})$, and CL had the lowest establishment costs at planting (\$19,000/ha). However, the low establishment cost of CL did not give a positive NPV (\$7000) until after 14 years with 'McIntosh'.

The quickest time to a positive NPV was 5 years for 'Honeycrisp' with TS on 'B.9', whereas CL with 'M.M.111' had the latest
BYPNPV, 9 years (Fig. 1). With 'McIntosh', BYPNPV was reached at 9 years for TS with 'M.9', 10 years with 'B.9', and 11 years on either TS with 'G.16' or VA with 'M.9'. More time was needed for SA with 'M.9' (12 years), followed by VA on either 'B.9' or 'G.16', SA with 'B.9', and SP with 'G.30', all with a BYPNPV at 13 years. SA with 'G.16', SP with 'M.26', and CL with 'M.M.111' needed 14 years.

There was a different behavior for each cultivar and training system when studying the relationship of NPV to tree density after 1, 5, 10, 15, and 20 years (Fig. 2). Higher negative NPV values were observed when increasing tree density after 1 year. For 'Honeycrisp' at year 1, cumulative NPV was $-\$ 20,000 /$ ha for 500 trees/ha, whereas it was $-\$ 50,000 /$ ha when planting 3230 trees/ha. At year 5, cumulative NPV of 
Table 18. Cumulative net present value (NPV, \$/ha) for each combination of training system (Central Leader - CL, SolAxe - SA, Slender Pyramid - SP, Tall Spindle - TS, and Vertical Axis - VA) and rootstock ('M.M.111', 'B.9', 'G.16', 'M.9', 'G.30', and 'M.26') for 'Honeycrisp' and 'McIntosh' at Peru, Clinton County, NY, over 20 years. Means followed by different letters denote significant differences (Tukey's honestly significant difference, $P \leq 0.05$ ).

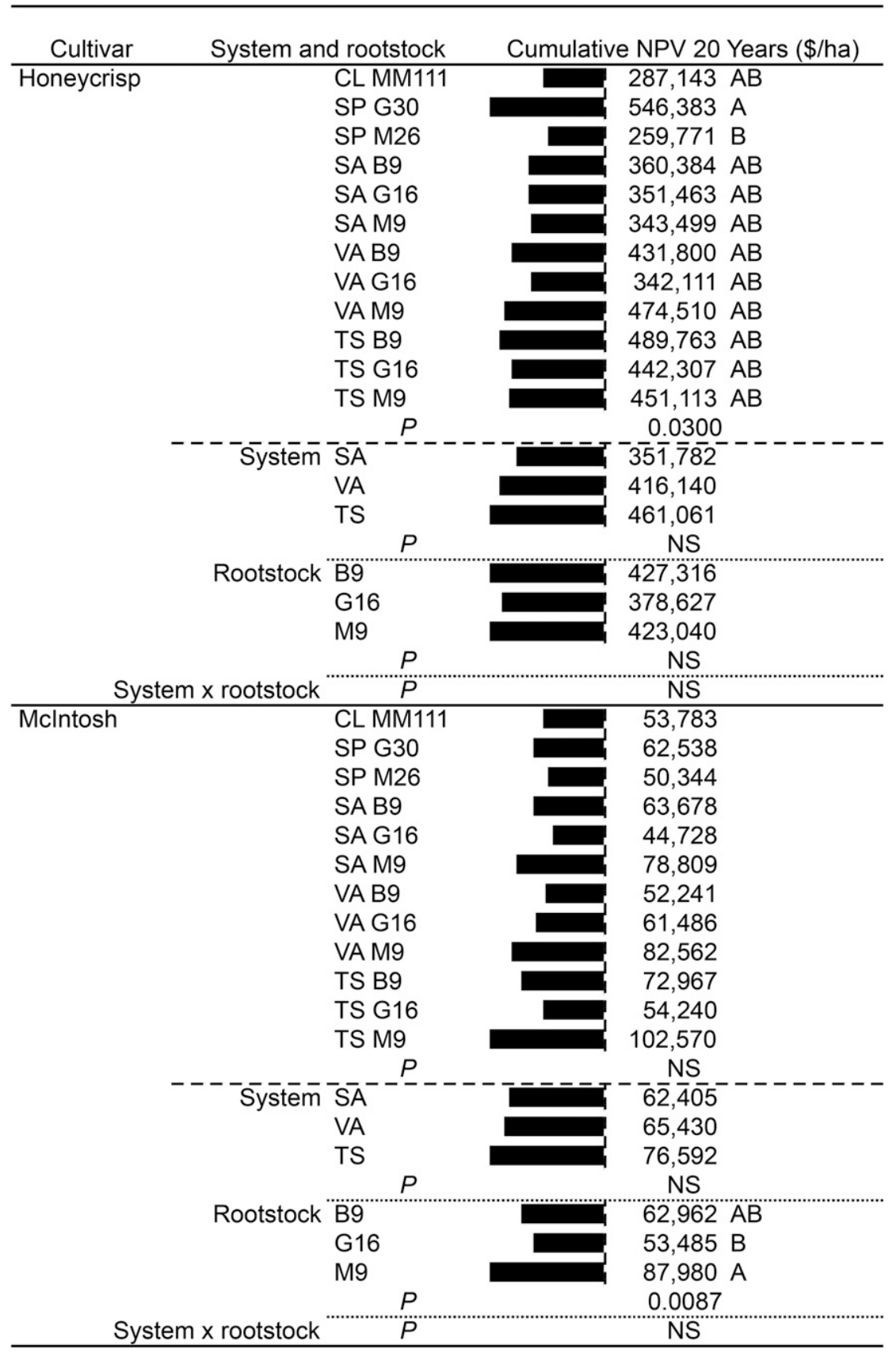

'Honeycrisp' almost reached a positive value for high-density plantings ( $>2500$ trees/ha), and the advantage of high-density plantings in NPV compared with low-density plantings became even greater after 10-20 years (\$450,000/ha vs. $\$ 330,000 /$ ha).

Similarly, 'McIntosh' had higher negative NPV values for high-density plantings after year 1 and were still significantly more negative than low-density plantings after year 5 , but the differences among planting densities were not great at that time (Fig. 2). After 10 years, differences among planting densities became more apparent, where negative NPV values were still observed for
'McIntosh', tree price had a greater effect. However, positive NPV values were still observed, even when tree price increased by $50 \%(\$ 19.4)$. Price increase tended to have a greater effect on high planting densities similar to what we observed for 'Honeycrisp', but at high tree prices, some 'McIntosh' high-density systems (e.g., TS with 'G.16' and 'B.9') were less profitable than the lowest density system (CL with 'M.M.111').

Changing the DR did not change how the ranking of the NPV of the different systems for either cultivar; however, there was a different response depending on the cultivar (Fig. 4). With 'Honeycrisp', a DR of $9 \%$ gave a similar NPV for SP with ' $G .30$ ' as $5 \%$ DR for SA. With 'McIntosh', the lowest NPV was observed for SA with 'G.16' when DR was $9 \%$. At $7 \%$ of DR, TS with 'M.9' had higher NPV than most of the other treatments at $5 \% \mathrm{DR}$.

Yield fluctuation had a big impact on NPV (Fig. 5). 'Honeycrisp' was still profitable with all systems when yield decreased to $60 \%$. When yield was increased by $40 \%$, the highest NPV $(\$ 800,000 /$ ha) was for TS with 'B.9' and for SP with 'G.30'. At 140\% yield, CL with 'M.M.111' gave similar NPV as TS with 'B.9' with the reference (trial) yield $(100 \%)$. For 'McIntosh', almost all the treatments were not profitable when yield decreased to $60 \%$, with the exception of SA, VA, and TS, all with 'M.9'. For systems with less than 1100 trees/ha, yield would have to be $140 \%$ of trial reference yield for the NPV of these low-density systems to equal or exceed the NPV of the high-density TS on 'M.9' with reference (trial) yield.

Similarly to yield fluctuation, fruit price had a huge impact on orchard NPV. A fruit price increase of $15 \%$ had a similar effect on NPV as $120 \%$ yield increase (Figs. 5 and 6 ). All the different training systems were profitable when fruit price decreased by $25 \%$, even 'McIntosh'. However, almost no profit was observed for SA and TS, both with 'G.16'. TS with 'M.9' had the highest NPV, with $\approx \$ 140,000 /$ ha when fruit price increased by $15 \%$ and increased to $\$ 160,000 /$ ha when price increased by $25 \%$. For 'Honeycrisp', NPV increased to $\$ 700,000$ for SP with 'G.30' and \$600,000 for TS with 'B.9' when price increased by $25 \%$. All 'Honeycrisp' treatments were profitable even when fruit price dropped by $25 \%$.

Land cost did not have an important impact on orchard NPV for 'Honeycrisp', with all of the systems remaining profitable, even when land cost was $\$ 15,000 /$ ha (Fig. 7). For 'McIntosh', all the systems were still profitable when land cost increased; yet, it was more affected than 'Honeycrisp'. For instance, with 'McIntosh', the lowest planting densities experienced the greatest reduction in NPV when land cost increased.

Labor cost had only a slight impact on orchard NPV with 'Honeycrisp', with the largest effect at the highest planting densities (Fig. 8). With 'McIntosh', labor cost affected more uniformly across different planting 
Cumulative NPV per ha - Honeycrisp

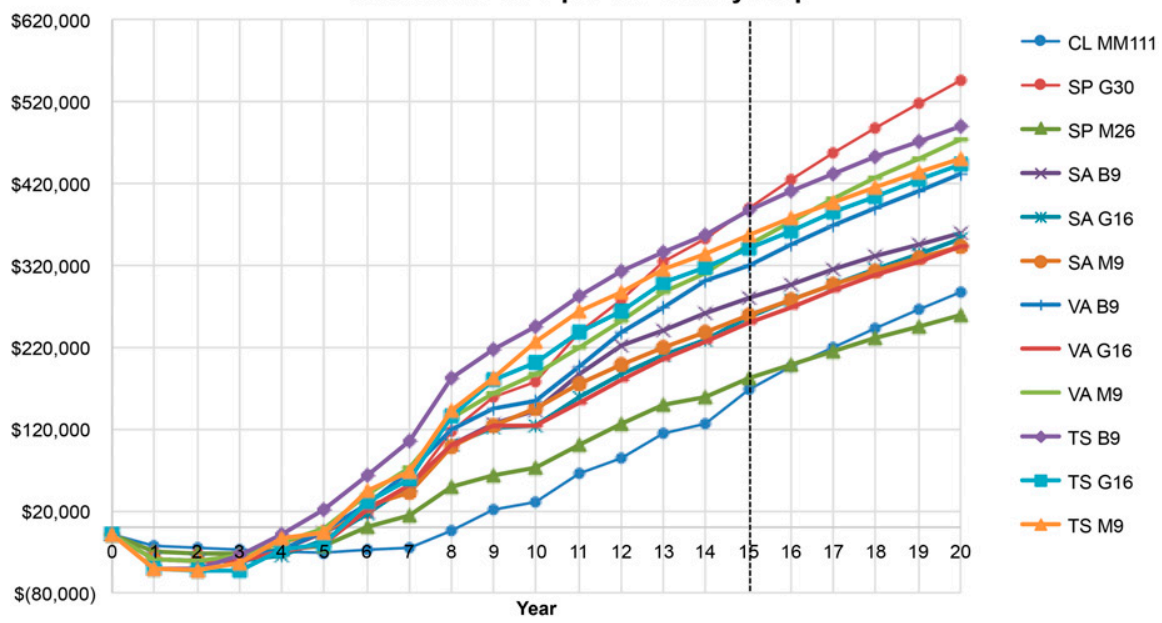

Cumulative NPV per ha - Mclntosh

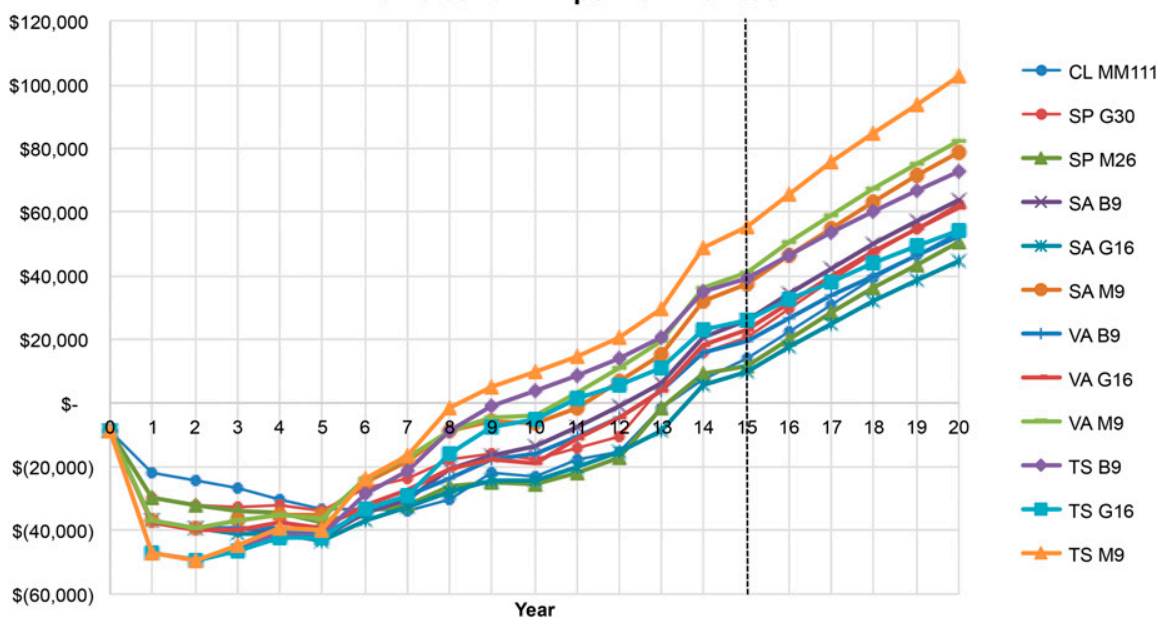

Fig. 1. Net present value (NPV) for each combination of training system (Central Leader - CL, SolAxeSA, Slender Pyramid-SP, Tall Spindle-TS, and Vertical Axis-VA) and rootstock ('M.M.111', 'B.9', 'G.16', 'M.9', 'G.30', and 'M.26') for 'Honeycrisp' and 'McIntosh' at Peru, Clinton County, NY. Average data from 2014 to 2016 was used to estimate values for years 16-20.

densities, with higher affects for the lowest planting densities $(<1100$ trees/ha).

We performed two PCA analyses to study the relation among the different variables that can affect NPV (Fig. 9). The first two principal components (PCs) were able to explain $92 \%(62 \% \mathrm{PC} 1$ and $30 \% \mathrm{PC} 2)$ and $96 \%$ (78\% PC1 and 18\% PC2) of the overall variance for 'Honeycrisp' and 'McIntosh', respectively. For both cultivars, yield and fruit price were the most important variables for the definition of the first PC, which were also positively correlated with NPV. Labor cost was the third variable in importance affecting NPV but negatively correlated in this case. Discount rate had different affection depending on the cultivar, with higher effect on 'McIntosh' than on 'Honeycrisp'. For both cultivars, DRs at $7 \%$ to $9 \%$ were highly positively correlated among them, being highly negatively correlated with DR at $3 \%$, which had a totally opposed effect on NPV in this case, especially for 'McIntosh'. Tree price also had higher negative effect on 'McIntosh' than on 'Honeycrisp', whereas the land cost had a similar negative correlation with NPV for both cultivars. Land cost and DR were extremely correlated for 'McIntosh'.

\section{Discussion}

Economic and sensitivity analyses. Our economic analysis showed that there was a very large difference $(5 \times)$ in NPV between the two cultivars with 'Honeycrisp' much more profitable than 'McIntosh'. Although 'Honeycrisp' had lower yields in this trial in northern New York (Lordan et al., 2018b), the high fruit prices for this cultivar made it highly profitable, with more than $\$ 450,000$ / ha over 20 years. This value is much higher than that estimated by Bradshaw et al. (2016) in Vermont, of $\$ 75,000 /$ ha after 20 years. However, in that case, only 725 trees/ha were used. In our study, NPV for 'Honeycrisp' was highly positively correlated with planting density. Thus, the highest NPV was estimated when training as TS (3230 trees/ha), followed by VA (1794 trees/ha), whereas SP (1097 trees/ha) with 'M.26', and CL (539 trees/ha) with 'M.M.111' were the systems with lowest NPV values. An exception to this relationship was SP with 'G.30'. This rootstock was released in 1994 and was described as a very productive and cold hardy semidwarf rootstock (Robinson et al., 2003). The present study shows that it has excellent yield potential in cold climates and even when planted at medium densities can be very profitable. Previous studies performed in Europe (Balkhoven-Baart et al., 2000; Weber, 2001) with other cultivars and other rootstocks, have all suggested much higher densities (3000-6000 trees/ha) as the most profitable option. However, it appears NPV for a given training system and planting density is also a function of rootstock and how well it is adapted to the climate. For instance, whereas SP with 'M.26' had the lowest cumulative NPV, SP with 'G.30' had the highest NPV and numerically higher than TS with 'M.9', although not statistically different. This was largely due to the advantages in yield with 'G.30' compared with 'M.26'. Most of the efforts during the last decade have been focused on dwarfing rootstocks for high-density plantings rather than semidwarf for mid-densities (Autio et al., 2011; Fazio, 2014; Fazio et al., 2014; Marini et al., 2014). However, the use of semidwarfing rootstocks for mid-density plantings could still be an option with certain conditions. One of the limiting factors with other semidwarfing rootstocks is precocity. However, ' $\mathrm{G} .30$ ', which is a semidwarfing rootstock, has similar precocity (earliness to bear fruit in the life of the orchard) to 'M.9'. The effect of precocity on NPV is large. After $\approx 5$ years, 'Honeycrisp' with TS (3230 trees/ha) on 'B.9' had a positive NPV in our study, whereas 9 years were needed when planting 539 trees/ha on 'M.M.111'. Similarly, in a study of Badiu et al. (2015) in Romania, 4 years were reported to payback with high-density plantings (3175 trees/ha), whereas up to 10 years were needed for low densities (333 trees/ha); however, payback is not perfectly comparable with NPV because the former does not consider an investment recoup with interest.

Comparing our study with previous studies made in Switzerland, Germany, The Netherlands, and France (Bravin et al., 2009; Weber, 2001), two of the most important variables affecting orchard NPV in our trial were fruit price and yield. Tree price was important, especially for highest densities, mainly because of the higher investment risk that is required in these cases. However, the higher returns that growers are getting for 'Honeycrisp' make this cultivar profitable despite tree price increases. In another study that we performed with other cultivars such as McIntosh, Fuji, and Empire, mid- to high densities (>2200 trees/ha) were highly affected when tree price increased, most likely because of the low fruit price of those cultivars (Lordan et al., 2018a). Greater planting density increases establishment costs and makes a risky investment, but this 

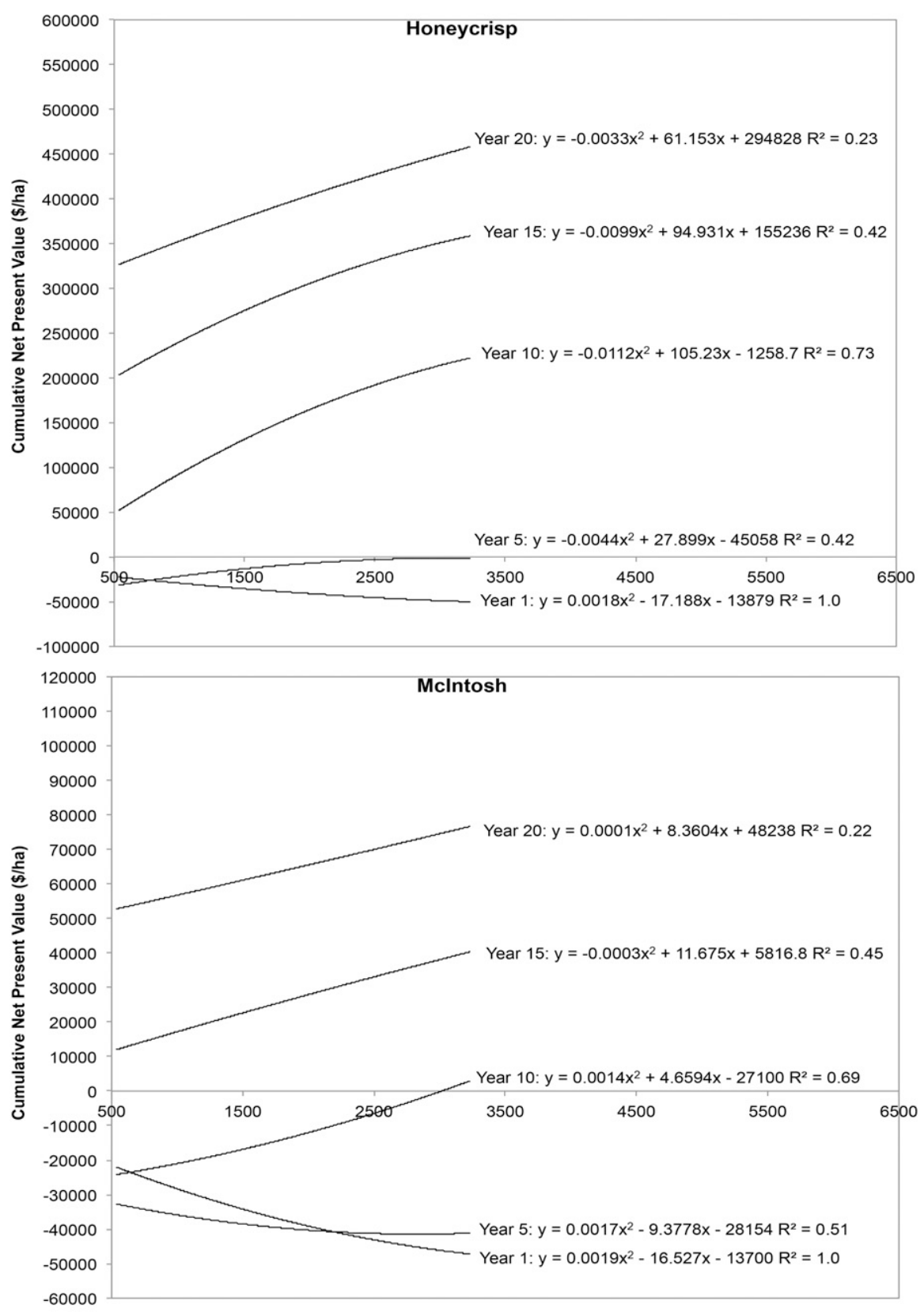

Planting density (trees/ha)

Fig. 2. Regressions for yearly cumulative net present value to tree density (trees/ha) for each cultivar (Honeycrisp and McIntosh) at Peru, Clinton County, NY.

can be accepted if a cultivar such as 'Honeycrisp', with high fruit price, is planted. Even a reduction of $25 \%$ in fruit price or a yield decrease to $60 \%$ was still profitable for this cultivar. Thus, if higher yields could be achieved by using new rootstocks (Lordan et al., 2016, 2017b; Reig et al., 2018; Robinson et al., 2011a, 2016), a possible future fruit price reduction could be offset.

Coinciding with 'Honeycrisp', the optimum planting density for 'McIntosh' was 3230 trees/ha; however, NPV was considerably lower for this cultivar $(\$ 100,000 /$ ha vs. $\$ 500,000 /$ ha, after 20 years). In a previous study, we estimated an NPV of $\$ 40,000 /$ ha after 20 years, but optimum planting density was slightly lower in that case (2500 trees/ha), higher yields could be achieved while keeping high fruit quality. In addition, labor cost increases will be more detrimental for cultivars such as McIntosh than Honeycrisp. The great effect on NPV that we observed with 'McIntosh' when increasing either the land cost or the DR, suggest that this cultivar would be only profitable in the future when high productivity can be attained. Thus, we suggest that the TS plantings (3230 trees/ha) is the best option with dwarfing rootstocks such as 'M.9' or newer Geneva ${ }^{\circledR}$ rootstocks other than 'G.16'. This differs from the optimum density observed in WNY (2500 trees/ha) (Lordan et al., 2018a), where lower planting densities were more suitable to reduce the investment cost because of the lower fruit quality that can be produced in those areas. In addition, the great impact of labor cost could be reduced through mechanization or robotic technology (Bulanon et al., 2002; Markman, 2017; Zhang and Karkee, 2016).

\section{Conclusions}

Yield and fruit price were the main variables that affected NPV, followed by labor cost. Therefore, the best approach for growers is to increase orchard yield at the same time reducing labor input and increasing fruit quality to obtain higher fruit prices. It is difficult to quantify the level of risk associated with the different planting options. Yet, when two options have the same NPV, the one with the lower initial investment is preferred (White and DeMarree, 1992). However, with cultivars like Honeycrisp that have high grower returns, more risky investments can be adopted because of their quicker BYPNPV. In these cases, high-density plantings in TS on dwarfing rootstocks seemed to be the best option. Differences between lowand high-density plantings could get even greater if orchard life is increased, for instance from 15 to 20 years. Low number of years to recoup the investment gives growers flexibility to respond to changes in varietal demand. Taking into account NPV and BYPNPV from our trial, the best option would be to plant 'Honeycrisp' trained as a TS (3230 trees/ha) with either 'B.9' or 'M.9'. We estimate that planting 'McIntosh' is a higher risk decision because time spans of 12 years are required to recover the investment. However, planting low densities $(<1000$ trees/ha) that require less initial input may even be riskier because lower yields are achieved and this cultivar has much lower market price. Nonetheless, the premium fruit quality of 'McIntosh' grown in cold areas such as Champlain Valley leaves this cultivar as still a good alternative. Therefore, because high-density plantings have quicker payoffs, despite being more affected by tree and labor price increases and fruit price decreases; they seem to be the best option for cultivars such as 'McIntosh' in Champlain Valley. According to our study, the most profitable option for 'McIntosh' was TS with 'M.9', at 3230 trees/ha. 

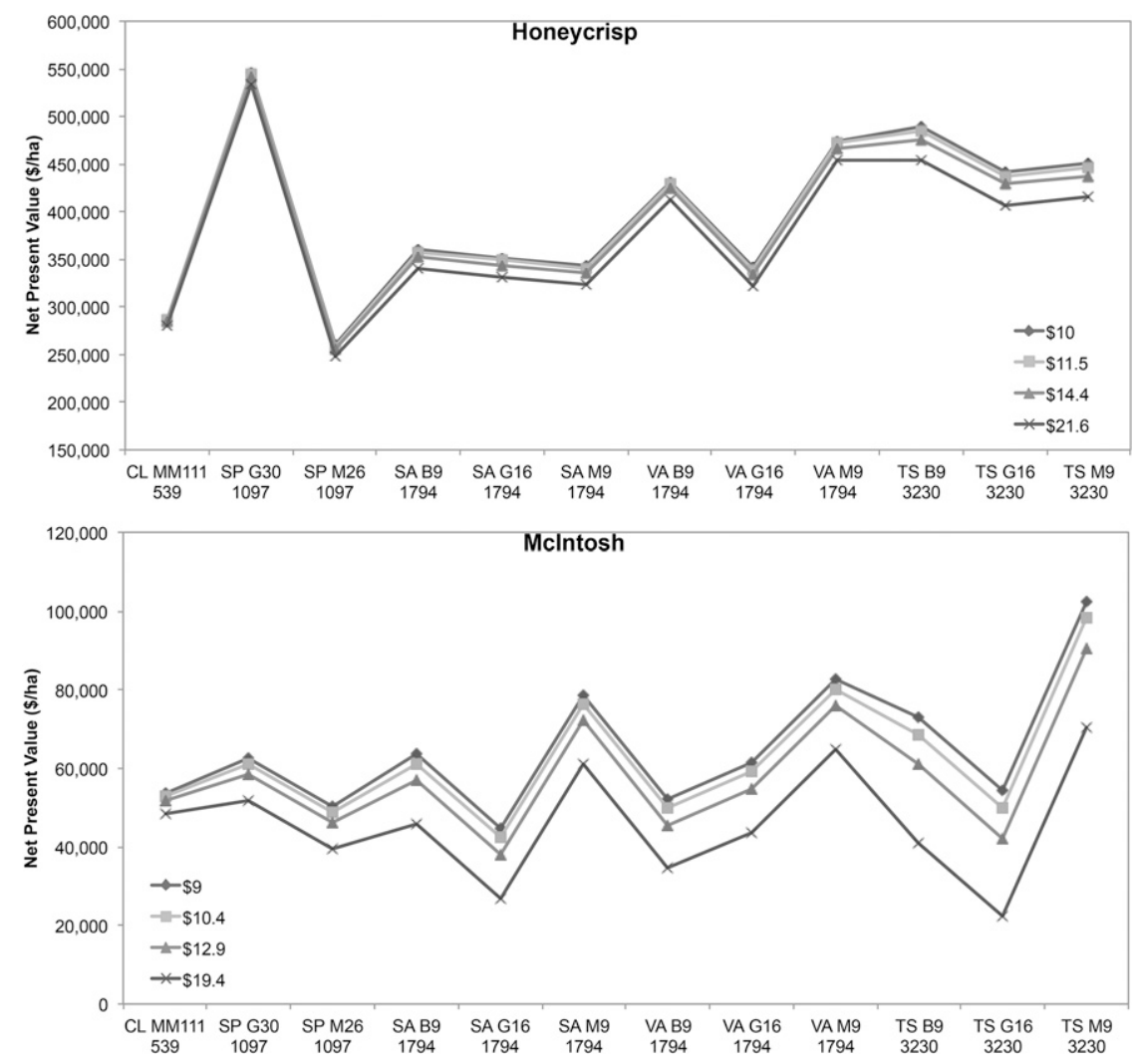

Fig. 3. Effect of tree price on net present value after 20 years of each combination of training system (Central Leader - CL, SolAxe-SA, Slender Pyramid — SP, Tall Spindle-TS, and Vertical Axis-VA) and rootstock ('M.M.111', 'B.9', 'G.16', 'M.9', 'G.30', and 'M.26') for 'Honeycrisp' and 'McIntosh' at Peru, Clinton County, NY. Note different $y$-axis scales and tree prices depending on cultivar. Tree prices reflect $15 \%, 25 \%$, and $50 \%$ increase to reference tree price (Table 4$) . * 0.5 /$ tree is discounted when more than 1000 trees $/$ ha.
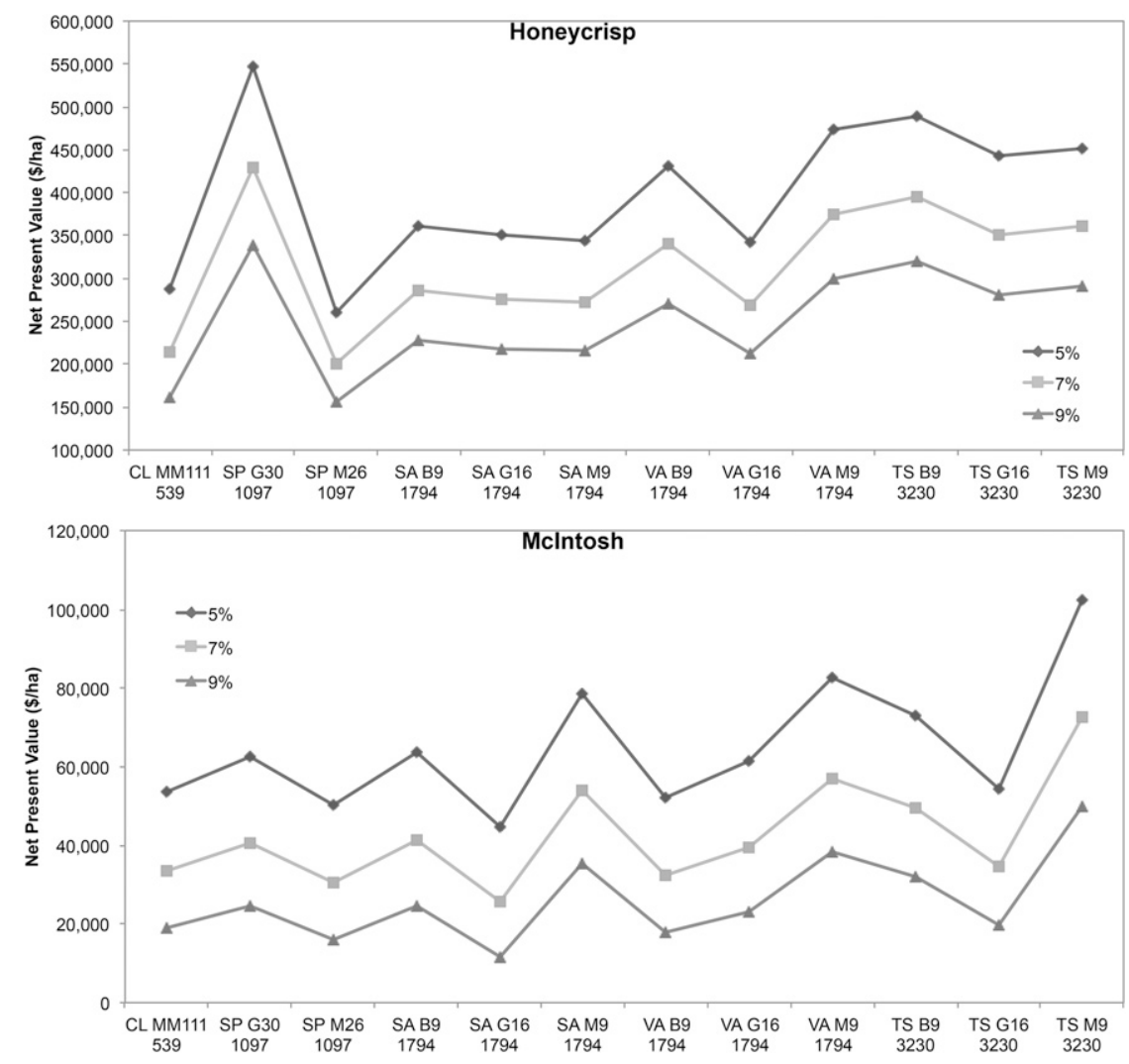

Fig. 4. Effect of discount rate ( $5 \%, 7 \%$, and $9 \%)$ on net present value after 20 years of each combination of training system (Central Leader-CL, SolAxe-SA, Slender Pyramid-SP, Tall Spindle_TS, and Vertical Axis_VA) and rootstock ('M.M.111', 'B.9', 'G.16', 'M.9', 'G.30', and 'M.26') for 'Honeycrisp' and 'McIntosh' at Peru, Clinton County, NY. Note different $y$-axis scales depending on cultivar. 

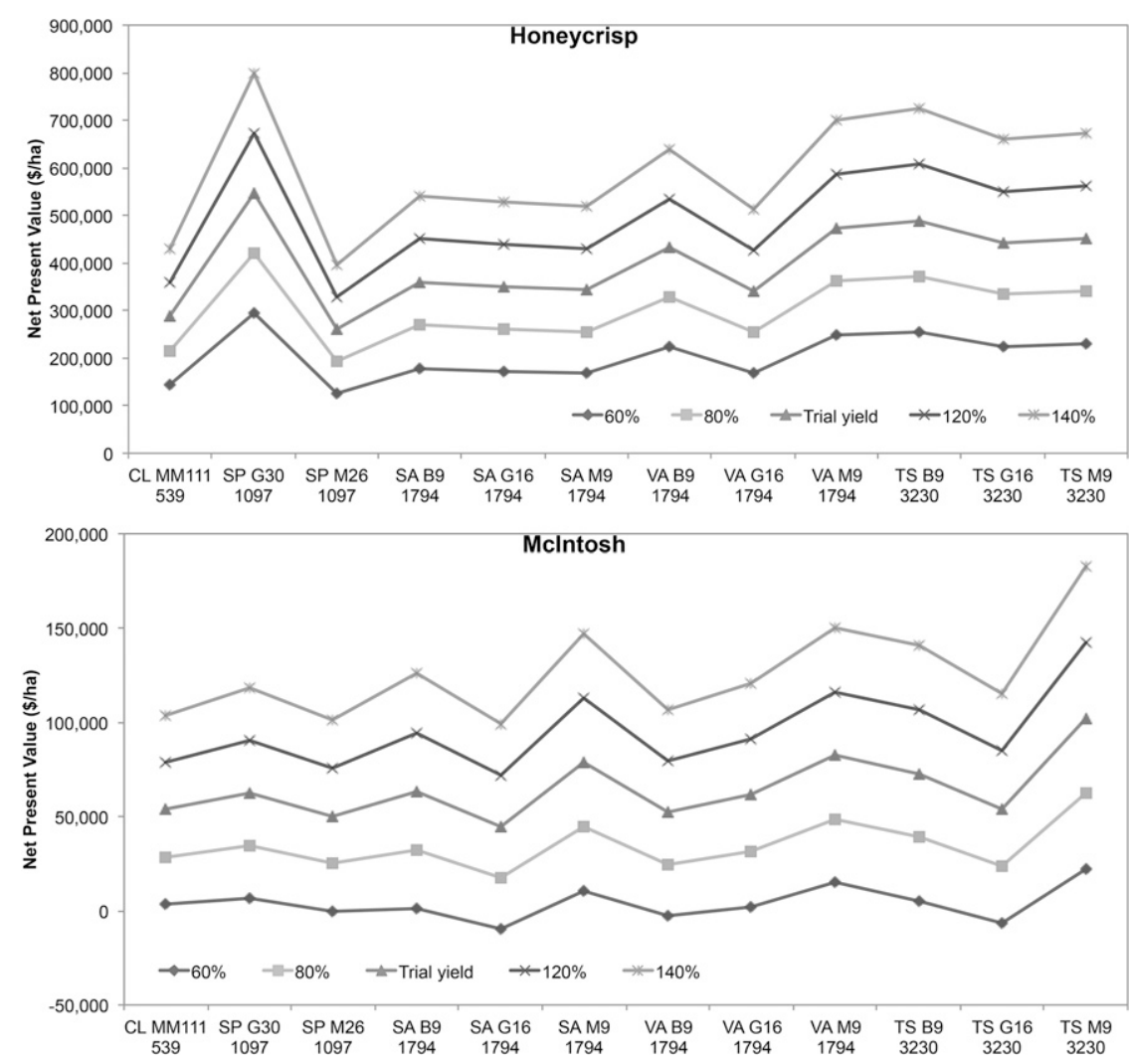

Fig. 5. Effect of yield level on net present value after 20 years of each combination of training system (Central Leader-CL, SolAxe-SA, Slender Pyramid-SP, Tall Spindle-TS, and Vertical Axis-VA) and rootstock ('M.M.111', 'B.9', 'G.16', 'M.9', 'G.30', and 'M.26') for 'Honeycrisp' and 'McIntosh' at Peru, Clinton County, NY. Note different $y$-axis scales depending on cultivar. Yield levels reflect $60 \%, 80 \%, 120 \%$, and $140 \%$ variation to average yield obtained from the trial.
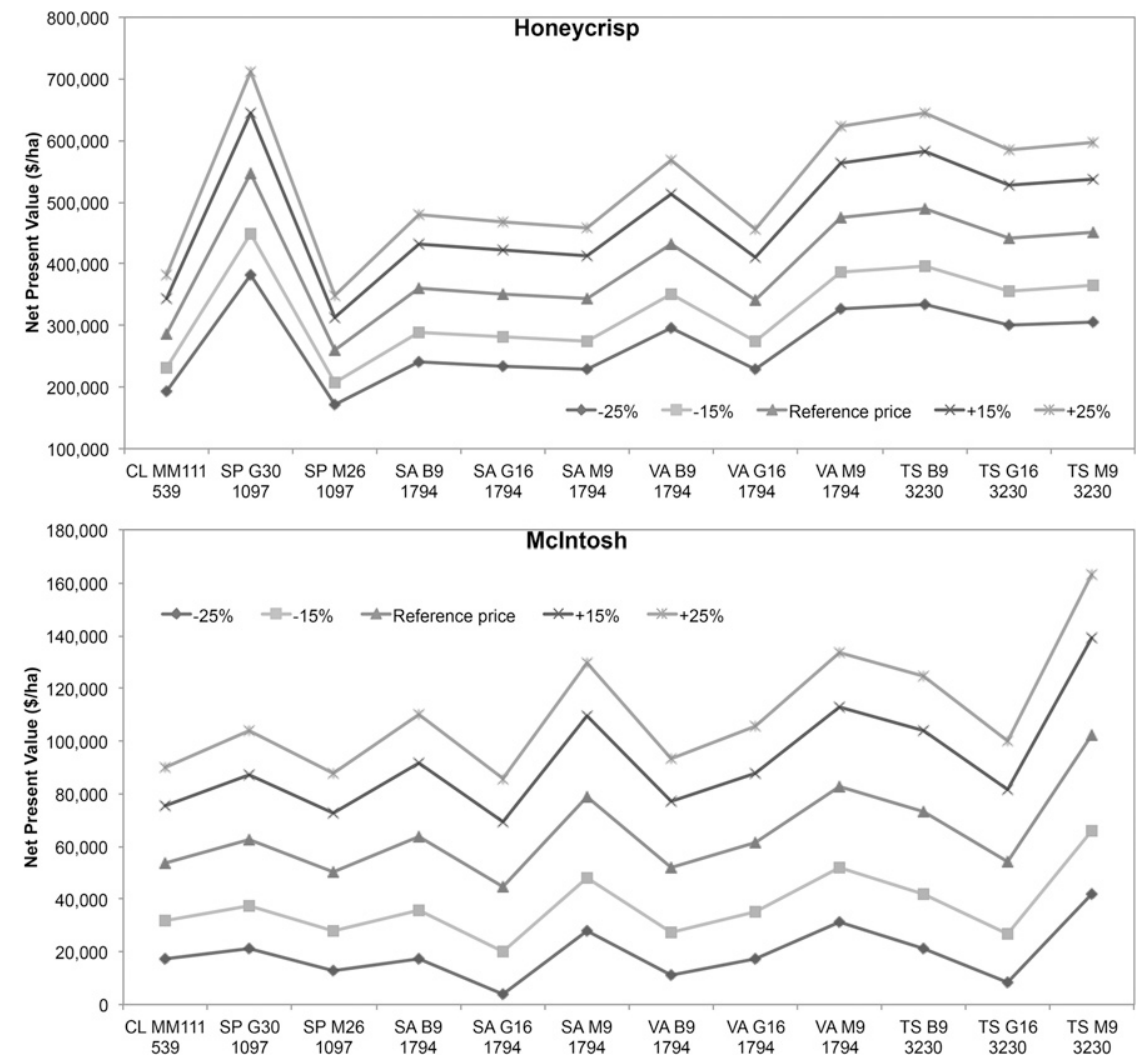

Fig. 6. Effect of fruit price on net present value after 20 years of each combination of training system (Central Leader - CL, SolAxe-SA, Slender Pyramid-SP, Tall Spindle-TS, and Vertical Axis-VA) and rootstock ('M.M.111', 'B.9', 'G.16', 'M.9', 'G.30', and 'M.26') for 'Honeycrisp' and 'McIntosh' at Peru, Clinton County, NY. Note different $y$-axis scales and tree prices depending on cultivar. Tree prices reflect $-25 \%,-15 \%,+15 \%$, and $+25 \%$ variations to reference fruit price (Table 2). 

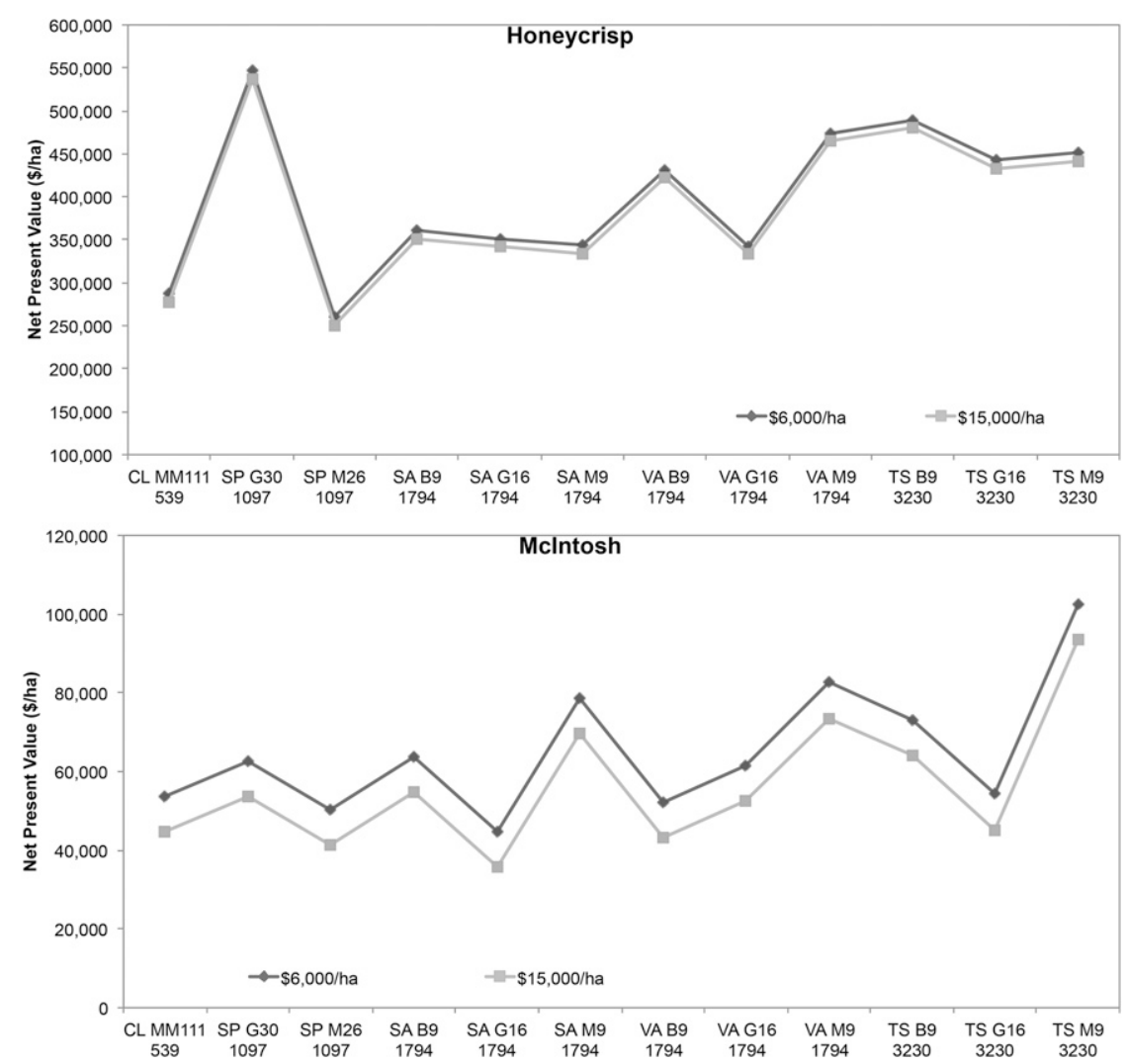

Fig. 7. Effect of land cost on net present value after 20 years of each combination of training system (Central Leader-CL, SolAxe-SA, Slender Pyramid-SP, Tall Spindle-TS, and Vertical Axis-VA) and rootstock ('M.M.111', 'B.9', 'G.16', 'M.9', 'G.30', and 'M.26') for 'Honeycrisp' and 'McIntosh' at Peru, Clinton County, NY. Note different $y$-axis scales depending on cultivar.
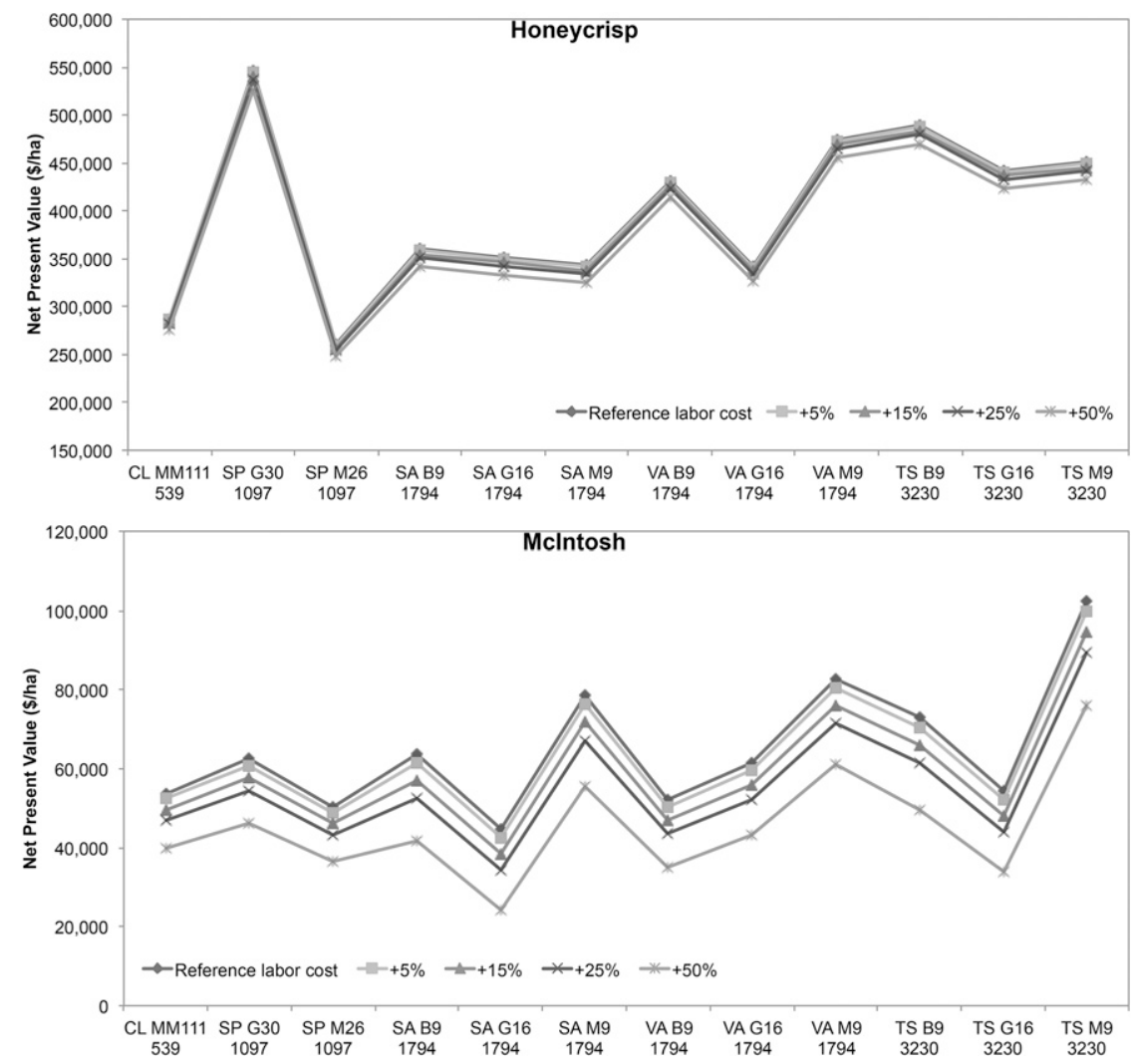

Fig. 8. Effect of labor cost price on net present value after 20 years of each combination of training system (Central Leader-CL, SolAxe-SA, Slender Pyramid-SP, Tall Spindle-TS, and Vertical Axis_VA) and rootstock ('M.M.111', 'B.9', 'G.16', 'M.9', 'G.30', and 'M.26') for 'Honeycrisp' and 'McIntosh' at Peru, Clinton County, NY. Note different $y$-axis scales depending on cultivar. Labor cost reflects $+5 \%,+15 \%$, $+25 \%$, and $+50 \%$ variations to reference labor cost (Tables 3 and 4) 

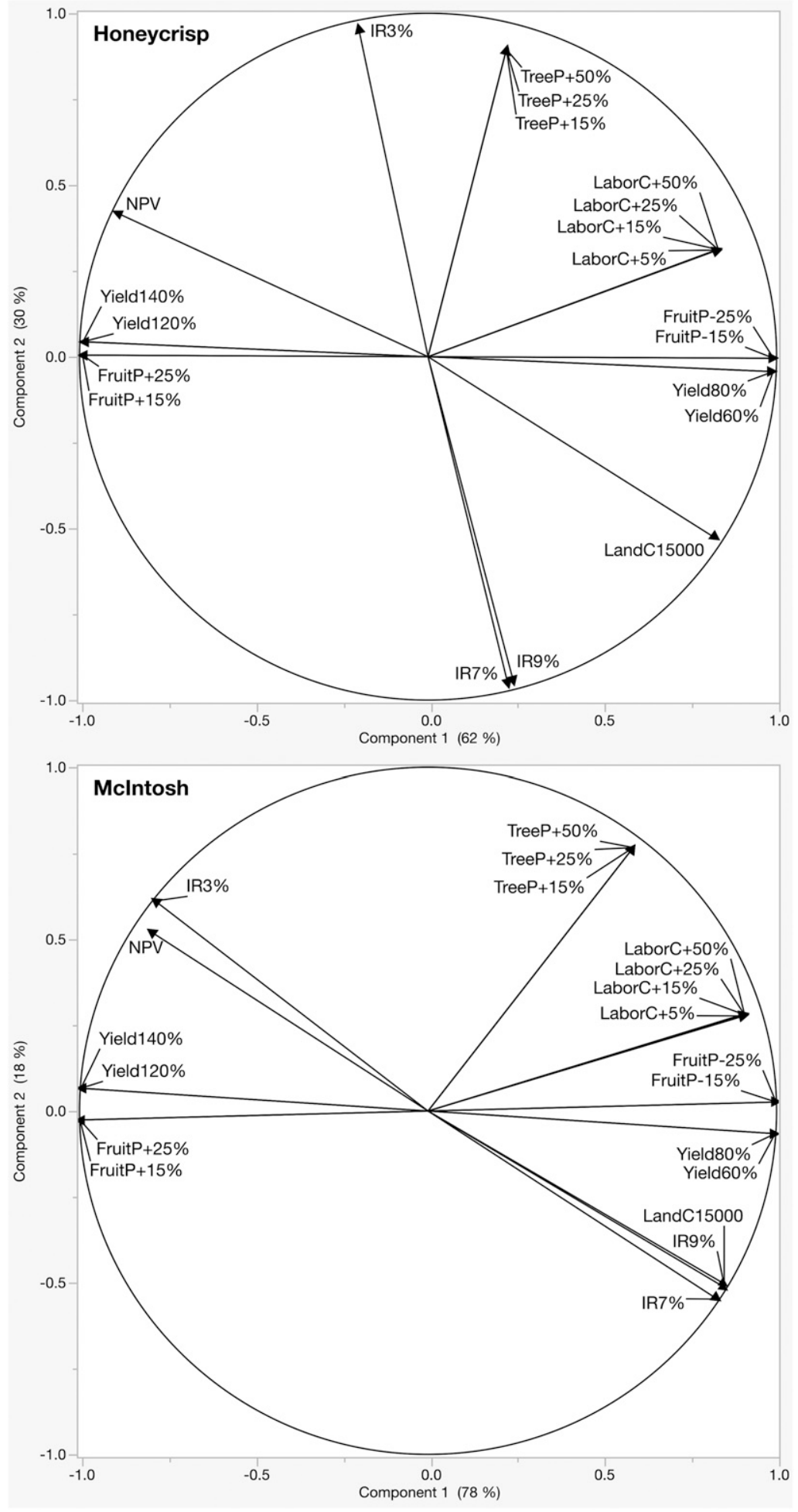

Fig. 9. Variable loadings represented in the plane defined by the first two principal components analysis for 'Honeycrisp' and 'McIntosh' sensitivity analyses. Variables are net present value; reference tree price (Table 4) (TreeP) increased by $15 \%, 25 \%$, and $50 \%$; reference fruit price (Table 2) (FruitP) reduced and increased by $15 \%$ and $25 \%$; average yield obtained from the trial modified to $60 \%, 80 \%, 120 \%$, and $140 \%$; land cost (LandC) at $\$ 15,000 /$ ha, discount rates (IR) at $7 \%$ and $9 \%$; and labor cost (LaborC) increased by $5 \%, 15 \%, 25 \%$, and $50 \%$.

\section{Literature Cited}

Agnello, A.M., A. Landers, D. Rosenberger, T.L. Robinson, J.E. Carroll, L. Cheng, P.D. Curtis, D.I. Breth, and S.A. Hoying. 2003. Pest management guidelines for commercial tree-fruit production. Cornell Univ., Ithaca, NY.
'Fuji' and 'McIntosh' apple trees after 10 years as affected by several dwarf rootstocks in the 1999 NC-140 apple rootstock trial. J. Amer. Pomol. Soc. 65(2):2-20.

Badiu, D., F.H. Arion, I.C. Muresan, R. Lile, and V. Mitre. 2015. Evaluation of economic efficiency of apple orchard investments. Sustainability 7(8):10521-10533.

Balkhoven-Baart, J., P. Wagenmakers, J. Bootsma, M. Groot, and S. Wertheim. 2000. Developments in Dutch apple plantings. Acta Hort. 513:261-270

Bradshaw, T.L., L.P. Berkett, R.E. Moran, M.E. Garcia, H.M. Darby, R.L. Parsons, S.L. KingsleyRichards, M.C. Griffith, S.C. Bosworth, and J.H. Gorres. 2016. Long-term economic evaluation of five cultivars in two organic apple orchard systems in Vermont, USA, 2006-2013. Acta Hort. 1137:315-321.

Bravin, E., A. Kilchenmann, and M. Leumann. 2009. Six hypotheses for profitable apple production based on the economic work-package within the ISAFRUIT Project. J. Hort. Sci. Biotechnol. 84(6):164-167.

Bulanon, D.M., T. Kataoka, Y. Ota, and T. Hiroma. 2002. AE-Automation and emerging technologies: A segmentation algorithm for the automatic recognition of Fuji apples at harvest. Biosyst. Eng. 83(4):405-412.

Casler, G.L., B.L. Anderson, and R.D. Aplin. 1993. Capital investment analysis; using discounted cash flows. Grid Publishing Company, Columbus, $\mathrm{OH}$.

Cummins, J.N. and H.S. Aldwinckle. 1983. Breeding apple rootstocks, p. 294-394. In: J. Janick (ed.). Plant breeding reviews. Springer, Boston, MA.

DeMaree, A. 1995. Critical factors in orchard profitability. Compact Fruit Tree 28:92-94.

DeMarree, A., T. Robinson, and S. Hoying. 2003. Economics and the orchard system decision. Compact Fruit Tree 36:42-49.

Elkins, R.B. and T.M. DeJong. 2002. Effect of training system and rootstock on growth and productivity of 'Golden Russet Bosc' pear trees. Acta Hort. 596:603-607.

Elkins, R.B., T.M. DeJong, K. Klonsky, and R. DeMoura. 2008. Economic evaluation of high density versus standard orchard configurations: Case study using performance data for 'Golden Russet Bosc' pears. Acta Hort. 800:739-746.

Fazio, G. 2014. Breeding apple rootstocks in the twenty-first century: What can we expect them to do to increase productivity in the orchard? Acta Hort. 1058:421-428.

Fazio, G., T.L. Robinson, and H.S. Aldwinckle. 2015. The Geneva apple rootstock breeding program. Plant Breed. Rev. 39:379.

Fazio, G., Y. Wan, D. Kviklys, L. Romero, R. Adams, D. Strickland, and T. Robinson. 2014. Dw2, a new dwarfing locus in apple rootstocks and its relationship to induction of early bearing in apple scions. J. Amer. Soc. Hort. Sci. 139(2):87-98.

Ferree, D.C. and I.J. Warrington. 2003. Apples: Botany, production and uses. CABI Publishing, Cambridge, MA.

Goedegebure, J. 1993. Economic aspects of superintensive apple orchards. Acta Hort. 349:285294.

Greene, D.W. and S.A. Weis. 2001. Evaluation and growing of Honeycrisp in New England. Compact Fruit Tree 34(4):100-103.

Heijerman, G., P. Roelofs, and M. Groot. 2015. Profitability of the Dutch growing system of 'Conference'. Acta Hort. 1094:233-238.

Kappel, F. and R. Brownlee. 2001. Early performance of 'Conference' pear on four training systems. HortScience 36:69-71. 
Lordan, J., S. Alegre, R. Montserrat, and L. Asin. 2017a. Yield and profitability of 'Conference' pear in five training systems in North East of Spain. Span. J. Agr. Res. 15(3):e0904.

Lordan, J., G. Fazio, P. Francescatto, and T.L. Robinson. 2016. Effects of apple (Malus $\times$ domestica) rootstocks on vigor and yield scion response. XI Intl. Symp. Integrating Canopy Rootstock Environ. Physiol. Orchard Systems. ISHS.

Lordan, J., G. Fazio, P. Francescatto, and T.L. Robinson. 2017b. Effects of apple (Malus $\times$ domestica) rootstocks on scion performance and hormone concentration. Scientia Hort. 225:96-105.

Lordan, J., M. Gomez, P. Francescatto, and T.L. Robinson. 2018a. Long-term effects of tree density and tree shape on apple orchard performance, a 20 year study-Part 2, economic analysis. Scientia Hort. https://doi.org/10.1016/ j.scienta.2018.03.031.

Lordan, J., A. Wallis, P. Francescatto, and T.L. Robinson. 2018b. Long-term effects of training systems and rootstocks on 'McIntosh' and 'Honeycrisp' performance, a 15-year study in a northern cold climate: Part 1: Agronomic analysis. HortScience 53:968-977.

Marini, R.P., B. Black, R.M. Crassweller, P.A. Domoto, C. Hampson, R. Mot, T. Robinson, M. Stasiak, and D. Wolfe. 2014. Performance of 'Golden Delicious' apple on 23 rootstocks at eight locations: A ten-year summary of the 2003 NC-140 dwarf rootstock trial. J. Amer. Pomol. Soc. 68(2):54-68.

Markman, J. 2017. This is how robots will pick off apple pickers, Forbes. 25 Apr. 2018. $<$ https:// www.forbes.com/sites/jonmarkman/2017/06/28/ this-is-how-robots-will-pick-off-apple-pickers/ print/>.
Merwin, I.A., R. Byard, T.L. Robinson, S. Carpenter, S.A. Hoying, K.A. Iungerman, and M. Fargione. 2001. Developing and integrated program for diagnosis and control of replant problems in New York apple orchards. New York Fruit Qrtly. 9(1):11-15.

Reig, G., J. Lordan, G. Fazio, M.A. Grusak, S. Hoying, L. Cheng, P. Francescatto, and T. Robinson. 2018. Horticultural performance and elemental nutrient concentrations on 'Fuji' grafted on apple rootstocks under New York State climatic conditions. Scientia Hort. 227:22-37.

Robinson, T. and S. Hoying. 1999. What we learned about tree support from the 1998 Labor-Day storm. New York Fruit Qrtly. 7(2):17-24.

Robinson, T.L. 2008a. The evolution towards more competitive apple orchard systems in the USA. Acta Hort. 772:491-500.

Robinson, T.L. 2008b. Performance of pear and quince rootstocks with three cultivars in four high density training systems in the Northeastern United States. Acta Hort. 800:793-801.

Robinson, T.L., H. Aldwinckle, G. Fazio, and T. Holleran. 2003. The Geneva series of apple rootstocks from Cornell: Performance, disease resistance, and commercialization. Acta Hort. 622:513-520.

Robinson, T.L., A.M. DeMarree, and S.A. Hoying. 2007. An economic comparison of five high density apple planting systems. Acta Hort. 732:481-489.

Robinson, T.L., G. Fazio, S.A. Hoying, M. Miranda, and K. Iungerman. 2011a. Geneva rootstocks for weak growing scion cultivars like 'Honeycrisp'. New York Fruit Qrtly. 19(2):10-16.

Robinson, T.L., G. Fazio, J. Lordan, P. Francescatto, and B. Black. 2016. 2015 Progress report: Evaluation of the Cornell-Geneva apple rootstocks and other promising apple rootstocks. Compact Fruit Tree 49(1):16-19.

Robinson, T.L., S.A. Hoying, and G. Fazio. 2011 b. Performance of Geneva $(\mathrm{R})$ rootstocks in onfarm trials in New York State. Acta Hort. 903:249-255.

Robinson, T.L., S.A. Hoying, and G.H. Reginato. 2011c. The tall spindle planting system: Principles and performance. Acta Hort. 903:571-579.

Robinson, T.L., J. Lordan, D. Dragoni, A.N. Lakso, and P. Francescatto. 2017. Precision irrigation management of apple with an apple-specific Penman-Monteith model. Acta Hort. 1150: 245-250.

Sansavini, S. and S. Musacchi. 2002. European pear orchard design and HDP management: A review. Acta Hort. 596:589-601.

Torres, E., I. Recasens, J. Lordan, and S. Alegre. 2017. Combination of strategies to supply calcium and reduce bitter pit in 'Golden Delicious' apples. Scientia Hort. 217:179-188.

Vercammen, J. 1999. Dossier Poire (2eme partie)Systemes de plantation et de taille pour le poirier Conference. Fruit Belge 67(479):70-80.

Walsh, C.S., A.R. Ottesen, M.J. Newell, J.C. Hanson, and E.H. Leone. 2011. The effect of organic and conventional management programs on apple and Asian pear tree growth, productivity, expenses and revenues in a hot, humid climate. Acta Hort. 903:665-672.

Weber, M. 2001. Optimizing the tree density in apple orchards on dwarf rootstocks. Acta Hort. 557:229-234.

White, G. and A. DeMarree. 1992. Economics of apple orchard planting systems. Cornell Coop. Ext. Info. Bul. 227.

Zhang, Q. and M. Karkee. 2016. Fully automated tree fruit harvesting. Resource (St. Joseph Mich.) 23(6):16-17. 